\title{
Environmental fate and effects of water-soluble synthetic organic polymers used in cosmetic products
}

\author{
Karen Duis ${ }^{*} \mathbb{D}$, Thomas Junker and Anja Coors
}

\begin{abstract}
Because of their usually high molecular weight, polymers are generally considered as being of low environmental concern and are, therefore, exempted from registration and evaluation within REACH. This exemption is currently being reviewed by the European Commission. Against this background, data on the environmental fate and effects of selected water-soluble synthetic organic polymers used in cosmetic products were evaluated. The considered polymers include non-ionic polyethylene glycols (PEGs), anionic homo- and copolymers of acrylic acid (AA-P\&CoPs), and cationic polyquaterniums (PQs). The PEGs are more amenable to biodegradation than the AA-P\&CoPs and the $P Q$ s, which biodegrade slowly. In wastewater treatment plants, sorption and precipitation are expected to lead to an effective removal of the considered polymers from the wastewater. Uptake and bioaccumulation in aquatic organisms are limited by the large molecular size and, for AA-P\&CoPs and PQs, the ionic charge of the polymers. In aquatic ecotoxicity tests, the PEGs and the AA-P\&CoPs showed generally no to low toxicity. Effects of AA-P\&CoPs on algae and crustaceans are attributed to the chelation of cationic nutrients in soft water, with toxicity being mitigated at higher water hardness. Toxicity of the cationic PQs to aquatic organisms ranged from absent to high, depending on the polymer structure, charge density and molecular weight, as well as on the test organism and test conditions. The observed effects most likely result from interactions with the organisms' surfaces. Aquatic toxicity of the PQs is reduced by dissolved organic carbon, suspended solids, sediments minerals, and at higher water hardness, representative of natural conditions. Results from toxicity tests with sediment and soil organisms were only identified for homopolymers of acrylic acid, showing no toxicity. The evaluation of the available ecotoxicity data suggests that test methods may need to be adapted to the respective polymer type, and further standardised to improve reproducibility. Based on the identified data, the considered polymers are likely to be of low environmental concern. However, this conclusion must be seen as preliminary, since environmental concentrations could not be estimated, and further ecotoxicity data are required, e.g., for sediment and soil organisms.
\end{abstract}

Keywords: Water-soluble polymers, Polycarboxylates, Polyethylene glycols, Polyquaterniums, Cosmetic products, Personal care products, Sorption, Biodegradation, Ecotoxicity, Mitigation

\section{Introduction}

Synthetic polymers are manufactured macromolecules consisting of one or more types of monomers that are covalently bound to each other. They represent a diverse

*Correspondence: k-duis@ect.de

ECT Oekotoxikologie GmbH, Böttgerstr. 2-14, 65439 Flörsheim/Main, Germany group of chemicals, with differences being primarily attributable to the type and number of monomer units $[1,2]$ (see Additional file 1 for the definition). According to the large diversity in the number of contained monomers, the molecular weight (MW) of polymers ranges from several hundred to several million Da [3]. Due to their usually high MW, polymers are generally considered as being of low environmental concern [2]. Therefore, they are exempted from registration and evaluation 
within the European REACH system until a scientifically and technically sound, practicable, and cost-efficient way has been identified for selecting certain polymers for registration [4]. However, monomers and other substances used to manufacture polymers need to be registered [2, 4]. According to Article 138 (2) of the REACH Regulation [4], the exemption of polymers from registration under REACH is currently being reviewed with the objectives (a) to analyse human health and environmental risks posed by polymers as compared to other chemicals, and (b) to evaluate if there is a need to register certain types of polymers. In this context, three reports were prepared for the European Commission. The first report [5] includes an evaluation of the registration requirements under REACH as compared to other regulations. The second report [6] suggests an approach for identifying polymers of low concern (PLC) that is relatively similar to the approach of the US EPA, which is based on criteria such as limited content of low MW material, limited presence of reactive functional groups, and no or low cationic charge density $[1,7]$. Similar PLC criteria are implemented in other countries $[5,6,8,9]$. The third report for the European Commission [10] summarised criteria to identify polymers that may require registration under $\mathrm{REACH}$ in the future and adapted the information requirements for these polymers. Polymers are also currently being addressed by ECETOC's Polymers Task Force, which proposed a conceptual framework for polymer risk assessment [9], and examined the applicability of chemical-analytical methods, standardised test methods, and predictive models [11].

Polymers sharing the same name and CAS number can differ in their MWs, monomer ratios, and other properties such as charge density [9]. To characterise a polymer, information is required on the identity and percentages of its constituents, the type of binding between them, the MW distribution including the percentage of low MW material $(<1 \mathrm{kDa})$, the ionic charge and charge density, the presence of reactive functional groups, and the water solubility [7, 12]. Synthetic polymers are polydisperse, i.e., they consist of polymer molecules with different numbers of monomer units and thereby different MWs. The number-average $\mathrm{MW}\left(\mathrm{MW}_{\mathrm{n}}\right)$, the weight-average $\mathrm{MW}\left(\mathrm{MW}_{\mathrm{w}}\right)$, and the polydispersity index $\left(\mathrm{MW}_{\mathrm{w}} / \mathrm{MW}_{\mathrm{n}}\right)$ can be used to characterise the MW of a polymer [3, 13] (see Additional file 1 for definitions). However, such information is often not publicly available.

The objectives of the present review are to critically evaluate information on the environmental fate, uptake into environmental organisms, and ecotoxicity for selected polymers, and to identify open research questions. Focus is placed on three classes of water-soluble synthetic organic polymers that are used in cosmetic products (as defined in [14]): non-ionic polyethylene glycols (PEGs), anionic homo- and copolymers of acrylic acid (AA-P\&CoPs), and cationic polyquaterniums (PQs).

The considered polymers were selected by the German Cosmetic, Toiletry, Perfumery and Detergent Association (IKW) based on a survey among its cosmetic industry member companies. They represent commonly used classes of polymers that are relevant, e.g., due to their tonnage or because they fulfil a specific function needed for the cosmetic product (for further details, see Additional file 1, Sect. 2). In cosmetic products, these polymers are used, e.g., as thickeners, emulsifiers, lubricants, conditioners, and film formers [15-17].

Apart from being used in cosmetic products, the selected polymers have numerous other applications. For instance, water-soluble homopolymers of acrylic acid (P-AAs) are employed in laundry detergents and other household cleaning products [18-21]. Water-soluble acrylamide-acrylic acid copolymers (AAmAA-CoPs) are used at high tonnages as flocculants, e.g., in wastewater treatment plants (WWTPs) [22-24], and as soil conditioners to improve water retention and reduce erosion of irrigated agricultural soils [25-27]. Polyquaternium-6 is widely used as coagulant and flocculent in wastewater treatment, for sludge dewatering and as coagulant in drinking water purification [23, 28-32]. PEGs have a variety of applications, e.g., for drug delivery, in household and industrial cleaning products and in hydraulic fracturing fluids $[16,33-36]$.

\section{Methods}

\section{Considered water-soluble synthetic organic polymers}

Information on the identity and key characteristics of the considered synthetic organic polymers is provided in Table 1 and in the Additional file. The selected polymers are all water-soluble ( $>1 \mathrm{mg} / \mathrm{L}$, see Additional file, Sect. 1 and Tables S1-S3). For the AA-P\&CoPs and PQs, chain lengths (and thus MWs), and, in case of heteropolymers, monomer ratios and charge densities may span across a considerable range. In the following, MWs without further specification are indicated, when more specific information (e.g., $\mathrm{MW}_{\mathrm{n}}$ and $\mathrm{MW}_{\mathrm{w}}$ ) is not available.

PEGs are homopolymers of ethylene oxide (i.e., polyethers). The ten considered PEGs have average MWs ranging from $200 \mathrm{Da}$ to $4000 \mathrm{kDa}$ (Table 1 and Additional file 1: Table S1). They are hydrophilic but, due to a lack of ionisable functional groups, neutral (non-ionic) molecules.

Due to their carboxylic groups, AA-P\&CoPs are anionic at neutral $\mathrm{pH}$. Homopolymers of acrylic acid (P-AA) used in cosmetics have MWs of approx. 2000$4000 \mathrm{kDa}$ and a charge density of $10.6 \mathrm{meq} / \mathrm{g}$ (see Additional file 1, Sect. 1 and Table S2). The considered 
Table 1 Water-soluble synthetic organic polymers considered in the present review

\begin{tabular}{|c|c|c|c|c|c|}
\hline $\begin{array}{l}\text { Considered polymer: } \\
\text { technical name }\end{array}$ & Systematic name ${ }^{a, b, c}$ & & CAS number ${ }^{a, b}$ & INCI name $e^{b, d}$ & Polymer class \\
\hline \multicolumn{6}{|c|}{ Non-ionic polymers: polyethylene glycols (PEGS) } \\
\hline PEG-200e & \multirow{10}{*}{$\begin{array}{l}\text { Poly(oxy-1,2-ethanediyl), } \\
\text { a-hydro- } \omega \text {-hydroxy- }\end{array}$} & (Average MW: 200 Da) & $25322-68-3^{f}$ & PEG-4 & \multirow[t]{10}{*}{ Polyethylene glycols } \\
\hline PEG-400 & & (Average MW: 400 Da) & $25322-68-3^{f}, 5117-19-1$ & PEG- $8^{e}$ & \\
\hline PEG-600 & & (Average MW: 600 Da) & $25322-68-3^{f}$ & PEG-12e & \\
\hline PEG-1000 & & (Average MW: 1000 Da) & & PEG-20 & \\
\hline PEG-1500 & & (Average MW: 1500 Da) & & PEG-32e & \\
\hline PEG-4000 & & (Average MW: 4000 Da) & & PEG-90e & \\
\hline PEG-6000 ${ }^{e}$ & & (Average MW: 6000 Da) & & PEG-150 & \\
\hline PEG-8000 & & (Average MW: 8000 Da) & & PEG-180 & \\
\hline PEG-20,000 & & $\begin{array}{l}\text { (Average MW: } \\
\text { 20,000 Da) }\end{array}$ & & PEG-450 & \\
\hline PEG-4,000,000 & & $\begin{array}{l}\text { (Average MW: } \\
\text { 4,000,000 Da) }\end{array}$ & & PEG-90 M & \\
\hline \multicolumn{6}{|c|}{ Anionic polymers: homo- and copolymers of acrylic acid (AA-P\&CoPs) } \\
\hline $\begin{array}{l}\text { Homopolymer of } \\
\text { acrylic acid (P-AA) }\end{array}$ & \multicolumn{2}{|c|}{ 2-Propenoic acid, homopolymer, sodium salt } & $9003-04-7,25549-84-2$ & Sodium Polyacrylate & \multirow[t]{2}{*}{$\begin{array}{l}\text { Polycarboxylates: } \\
\text { polyacrylates }\end{array}$} \\
\hline $\begin{array}{l}\text { Methacrylic acid-ethyl } \\
\text { acrylate copolymer } \\
\text { (MAEA-CoP) }\end{array}$ & \multicolumn{2}{|c|}{$\begin{array}{l}\text { 2-Propenoic acid, 2-methyl-, polymer with ethyl } \\
\text { 2-propenoate }\end{array}$} & $25212-88-8$ & Acrylate Copolymer ${ }^{g}$ & \\
\hline $\begin{array}{l}\text { Acrylamide-acrylic acid } \\
\text { copolymer (AAmAA- } \\
\text { CoP) }\end{array}$ & \multicolumn{2}{|c|}{$\begin{array}{l}\text { 2-Propenoic acid, polymer with 2-propenamide, } \\
\text { sodium salt }\end{array}$} & $\begin{array}{l}25085-02-3,25987-30- \\
\quad 8\end{array}$ & $\begin{array}{l}\text { Acrylamide/Sodium } \\
\text { Acrylate Copolymer }\end{array}$ & $\begin{array}{l}\text { Polycarboxylates: } \\
\text { polyacrylamides }\end{array}$ \\
\hline \multicolumn{6}{|c|}{ Cationic polymers: polyquaterniums (PQs) } \\
\hline $\begin{array}{l}\text { Polyquaternium- }{ }^{\mathrm{h}} \\
\text { (PQ-6) }\end{array}$ & \multicolumn{2}{|c|}{$\begin{array}{l}\text { 2-Propen-1-aminium, N,N-dimethyl-N-2-propen- } \\
\text { 1-yl-, chloride (1:1), homopolymer }\end{array}$} & $26062-79-3$ & Polyquaternium- $6^{\text {h }}$ & \multirow[t]{4}{*}{ Polyquaterniums } \\
\hline $\begin{array}{l}\text { Polyquaternium- } 7^{\text {h }} \\
\text { (PQ-7) }\end{array}$ & \multicolumn{2}{|c|}{$\begin{array}{l}\text { 2-Propen-1-aminium, N,N-dimethyl-N-2-propen- } \\
\text { 1-yl-, chloride (1:1), polymer with 2-propenamide }\end{array}$} & 26590-05-6 & Polyquaternium- $7^{\text {h }}$ & \\
\hline $\begin{array}{l}\text { Polyquaternium-10 } \\
\text { (PQ-10) }\end{array}$ & \multicolumn{2}{|c|}{$\begin{array}{l}\text { Cellulose, 2-(2-hydroxy-3-(trimethylammonium) } \\
\text { propoxy)ethyl ether, chloride }\end{array}$} & $\begin{array}{l}68610-92-4,53568-66- \\
4,54351-50-7,55353- \\
19-0,81859-24-7\end{array}$ & Polyquaternium-10h & \\
\hline $\begin{array}{l}\text { Polyquaternium-16 } \\
\text { (PQ-16) }\end{array}$ & \multicolumn{2}{|c|}{$\begin{array}{l}\text { 1H-Imidazolium, 1-ethenyl-3-methyl-, chloride, } \\
\text { polymer with 1-ethenyl-2-pyrrolidinone }\end{array}$} & $95144-24-4$ & Polyquaternium-16 & \\
\hline
\end{tabular}

All considered polymers are used in cosmetic products

a Based on [39]

b Based on [40]

${ }^{c}$ Information on the molecular weight (MW) of the polyethylene glycols is part of their systematic name and therefore provided in column 2 . For information on the MW of the other polymers, see Additional file 1: Tables S2 and S3

d International Nomenclature of Cosmetic Ingredients (INCI) names are used to identify cosmetic ingredients and to label cosmetic products in a harmonised way (see Additional file 1, Sect. 1)

e For the polyethylene glycols (PEGs), the technical names (column 1) are based on the average molecular weight (MW). The INCI names of the PEGs (column 4) refer to the average number of ethylene oxide (EO) monomers. For instance, a PEG with an average MW of 200 Da, which consists of 4 EO monomers, is termed PEG-200 (technical name) or PEG-4 (INCI name)

f Generic CAS number

$g$ Note that the INCI name 'Acrylate Copolymers' is used for copolymers of two or more monomers consisting of acrylic acid, methacrylic acid, or one of their simple esters, i.e., not only includes MAEA-CoP, but also other polymers (see, e.g., [40])

$\mathrm{h}$ Numbers of the polyquaterniums follow the numerical order of their INCI registration and do not characterise their chemistry

copolymers of acrylic acid (AA-CoPs), methacrylic acid-ethyl acrylate copolymer (MAEA-CoP) and acrylamide-acrylic acid copolymer (AAmAA-CoP), have MWs of approx. $500 \mathrm{kDa}$ and $>1000 \mathrm{kDa}$, respectively.
The percentages of monomers in these two copolymers and, thus, their charge density, can vary.

PQs are cationic polymers containing quaternary ammonium groups. PQ-6, a homopolymer of 
diallyldimethylammonium chloride (DADMAC), has a charge density of $6.2 \mathrm{meq} / \mathrm{g}$ (Additional file 1: Table S3). The considered PQ-6 grades have MWs of approx. 100$200 \mathrm{kDa}$. PQ-7 is derived by copolymerising acrylamide and DADMAC. In PQ-7 grades used in cosmetics, the percentages of DADMAC typically range from 25 to $50 \%$, charge densities from 0.7 to $6 \mathrm{meq} / \mathrm{g}$, and MWs from 100 to $5200 \mathrm{kDa}$. PQ-10 is produced by reacting hydroxyethyl cellulose with a trimethyl ammonium substituted epoxide. PQ-10 grades used in cosmetics have charge densities around $1 \mathrm{meq} / \mathrm{g}$ and MWs between approx. 100 and $5200 \mathrm{kDa}$. Controversial information is available on the MWs of some PQ- 10 grades (see Table S3 for details). PQ-16 is derived by copolymerisation of 1-vinyl-3-methyl-imidazolium chloride and vinylpyrrolidone. The considered PQ-16 grades have charge densities between approx. 2.2 and $6.1 \mathrm{meq} / \mathrm{g}$, increasing with increasing percentage of 1-vinyl-3-methyl-imidazolium chloride, and MWs of approx. 40 to $400 \mathrm{kDa}$.

All of the here considered water-soluble polymers are not cross-linked or only cross-linked to a very limited extent ( $\leq 0.05 \%$; see Additional file 1: Tables S1-S3). Extensive cross-linking of polymers leads to a loss of water solubility [37, 38].

\section{Compilation and evaluation of data on environmental fate and effects}

Data on the environmental fate of the considered polymers, their potential for uptake and accumulation in environmental organisms, and their effects on aquatic and terrestrial organisms were compiled in a literature search using Scopus. The keywords comprised identifiers for the polymers (names, synonyms, CAS numbers), processes (e.g., sorption, degradat*, bioaccumulat*, toxic*), compartment (e.g., environment, wastewater), and organisms (e.g., alga*, invertebrate*). The most relevant search terms were used in supplementary internet searches to identify non-peer-reviewed literature. Additional data (safety data sheets, technical information and the main endpoints of confidential studies) were provided by IKW member companies. Previous evaluations of the environmental fate and effects of polymers were also considered, e.g., [7, 41, 42]. References listed in relevant publications were checked for further information. Due to possible effects of formulation ingredients other than the considered polymers, ecotoxicity data for formulated products were not taken into account.

The collected data including information on the tested polymer (e.g., MW and charge density), the used test method, the test result, and the reference are provided in the Additional file 1: Tables S4-S11. Reliability of the data was assessed according to Klimisch et al. [43] using four reliability classes: (1) reliable without restriction,
(2) reliable with restrictions, (3) not reliable, and (4) not assignable. For a considerable amount of data (e.g., those from safety data sheets and those provided by IKW member companies), only information on the main study endpoints was available. These data were included, but due to the lack of more detailed information on methods and results, their reliability had to be classified as 'not assignable' in most cases. Similarly, data reported in secondary sources, e.g., $[18,19,31]$, are included and classified as 'not assignable', if the referenced original sources were not available (the original references are indicated in the SI). For data from HERA [19], the reliability classification as indicated in this report is adopted here, but could not be verified (see Additional file 1: Tables S6 and S10).

\section{Results and discussion Availability of data}

Some previous evaluations of the environmental fate and effects of polymers mainly relied on confidential data submitted by industry to the US EPA [7, 41, 44] or provided by the UK Environment Agency and manufacturers [42]. Most of the used data were condensed or coded and can, thus, not be related to individual polymers. Several other studies lack sufficient information on the identity of the tested polymer. This applies to data for, e.g., anionic polyacrylamides without further specification (anionic polyacrylamides include acrylamide-acrylic acid copolymers, but also copolymers of acrylamide with other acids [45]). In some publications, only trade names of the evaluated polymers are stated, which could not be traced back to individual polymers (this information is often considered proprietary).

Furthermore, the evaluation of the collected environmental fate and ecotoxicity data revealed that information on the characteristics of the tested polymers was often rather limited. For most tests, only a mean MW without further specification $\left(\mathrm{MW}_{\mathrm{n}}\right.$ or $\left.\mathrm{MW}_{\mathrm{w}}\right)$, was provided. In some cases, information on the MW was lacking or controversial. Information on charge density of anionic and cationic polymers was partly missing or rather general (e.g., "low" charge density). For the majority of the compiled data, no details were publicly available on the content of residual monomers, oligomers, additives, and impurities of the investigated polymers. Therefore, an evaluation of the contribution of residual monomers, additives, and impurities (e.g., catalyst remnants) to the potential environmental concern was in most cases not possible.

Often, only limited data were identified on the environmental fate and effects of the considered polymers within the MW ranges as used in cosmetics. To derive general conclusions and to illustrate trends regarding their environmental fate and effects, data for the respective 
polymers with lower or higher MW were therefore also included in the present review. Data obtained with other polymers were included in some cases (e.g., [46]), especially when the database for the considered polymers is scarce.

\section{Environmental fate of water-soluble synthetic organic polymers}

A considerable number of environmental fate data were identified for PEGs and P-AAs (mostly from [18] and [19]), while fate data for the considered copolymers of acrylic acid and the PQs were more scarce.

\section{Sorption and complexation}

Sorption behaviour of polymers is determined by hydrophilic (e.g., hydrogen bonding), hydrophobic (e.g., van der Waals' forces) and, for charged polymers, electrostatic interactions [47]. Because of the greater number of binding sites, sorption capacity generally increases with increasing MW of the polymer [48-50]. Sorption also depends on the chain architecture and molecular conformation of the polymer. Entangling of long polymer chains can, for instance, result in lower sorption to particulate material than expected based on the MW [49-51]. Due to the length of the polymers and the large number of binding sites, some binding sites are almost always attached to the adsorption surface, preventing desorption $[49,51-54]$. Based on so far limited scientific evidence, non-extractable residues (NERs) may be formed in sediments and sludge-treated soils [9].

Although there is clear evidence for the sorption and complexation behaviour of PEGs, AA-P\&CoPs and PQs in general, only few solid-water $\left(K_{\mathrm{d}}\right)$ and organic carbonwater $\left(K_{\mathrm{OC}}\right)$ partition coefficients for sewage sludge, sediments, and soils were identified for the here considered polymers (Additional file 1: Table S4).

Polyethylene glycols Podoll et al. [55] found that, despite their good water solubility, PEGs (MWs: $600 \mathrm{Da}, 1 \mathrm{kDa}$ ) showed considerable sorption to sediments (Table S4), probably due to hydrophilic interactions with negatively charged sediment surfaces. Sorption correlated positively with the MW of the polymer and with the clay content of the sediments, but not with the organic carbon $(\mathrm{OC})$ content of the sediment. With desorption rates of $17-37 \%$, sorption of these low MW PEGs was only partly reversible. Szymanski et al. [56] investigated sorption of PEGs [MW: not indicated (n.i.)] to native and formalin-preserved activated sludge using an experimental continuous activated sludge plant. The PEG concentrations on native sludge were 1.5-2.5 times lower than those on preserved sludge, a fact that was assumed to be due to biodegradation of the PEGs on the surface of native sludge (see below). Thus, the interpretation of sorption studies with PEGs can be complicated by simultaneous biodegradation processes. Steber and Wierich [57] investigated the fate of ${ }^{14} \mathrm{C}$-labelled PEG (400 Da) in a continuous-flow model WWTP. The ${ }^{14} \mathrm{C}$-mass balance at test end (d 3) indicated considerable sorption of this PEG (and potential degradation products) to the sludge: $41 \%$ of the applied radioactivity was detected in the sludge and only $4 \%$ in the effluent (Additional file 1: Table S4).

Homo- and copolymers of acrylic acid Anionic polycarboxylates such as the considered AA-P\&CoPs form complexes with divalent and polyvalent cations that precipitate if the concentration of the cations is sufficiently high $[18,19,48,58-61]$. For P-AA, binding to $\mathrm{Ca}^{2+}$ is expected to lead to the precipitation of the polymers in WWTPs and in most natural waters [60,61].

Anionic polycarboxylates strongly sorb to positively charged surfaces, e.g., calcium sulphate and calcium carbonate $[18,52,58]$. If sufficient divalent or polyvalent cations are available to overcome the repulsion between the anionic polymers and negatively charged surfaces (e.g., of sewage sludge and soil/sediment minerals such as clay), anionic polycarboxylates also sorb to these surfaces [24, $25,50,52]$. Hence, under environmentally relevant conditions, anionic polycarboxylates generally show strong sorption to activated sludge, soil particles, and other solids $[18,58,62]$. A $K_{\mathrm{d}}$ of $1,825 \mathrm{~L} / \mathrm{kg}$ was determined for sorption of P-AA (16.1 kDa) to activated sludge ([19], see Table S4). Note that AAmAA-CoPs with MWs ranging from approx. 3000 to approx. 20,000 kDa are used as flocculants in water treatment and are applied to soil for soil conditioning and erosion control. They cause agglomeration (flocculation) of suspended solids, and the formed agglomerates are removed by settlement or flotation [22, 24].

Polyquaterniums $\mathrm{PQs}$ and other cationic polymers strongly sorb to dissolved organic carbon (DOC), especially negatively charged DOC components (e.g., humic acids and lignin), and the resulting neutral complexes precipitate [7, 41, 63-65]. Sorption of PQs to humic acids increases with increasing charge density [66, 67] (Table S4). Moreover, PQs show strong sorption to negatively charged surfaces, e.g., of sewage sludge, other suspended solids, and sediment/soil minerals [12, 28]. For instance, PQ-6 (26 kDa, $6.2 \mathrm{meq} / \mathrm{g})$ had a strong tendency to form complexes with bentonite clay [68].

In this context, it should be pointed out that the highly charged PQ- 6 is also used as a coagulant and flocculent aid in wastewater treatment: it neutralises the charge of anionic DOC and suspended solids, which then agglomerate and flocculate together with the PQ-6 $[28,31]$. 


\section{Abiotic degradation}

Hydrolysis is generally not considered a significant route of degradation for synthetic polymers in the environment $[12,44]$. Photolysis is regarded as of limited relevance for polycarboxylates (including AA-P\&CoPs) and PEGs under environmental conditions [19, 24, 60, 69, 70]. For the considered PQs, no information was identified on photolysis.

\section{Biodegradation and removal in WWTPs}

Most synthetic polymers biodegrade slowly [7, 9, 12, 33]. Generally, biodegradation rates decrease with increasing MW. Accordingly, low MW constituents of a polymer are degraded more easily than higher MW material $[18,19$, $33,71-73]$. If polymers are too large for uptake by microorganisms, exoenzymes produced by some bacteria and fungi are crucial for the first steps of biodegradation, in which the polymer chains are cleaved into lower MW fragments. Fragments that are small enough for uptake into the cells can then be degraded by a wider range of microorganisms [74-76].

Polyethylene glycols PEGs are more accessible to biodegradation than the other considered polymers. The evaluated data show ready biodegradability of PEGs with MWs up to $4-14.6 \mathrm{kDa}$, depending on the test method, indicating rapid and ultimate degradation in WWTPs and in most environments [77], whereas PEGs with higher MWs are not readily biodegradable (see Table S5). In combined $\mathrm{CO}_{2} / \mathrm{DOC}$ tests, Bernhard et al. [71] recorded complete biodegradation (>90\% DOC removal, corresponding to 70-95\% $\mathrm{CO}_{2}$ evolution) for PEGs with MWs ranging from $250 \mathrm{Da}$ up to $57.8 \mathrm{kDa}$. While PEGs with a MW $\leq 14.6 \mathrm{kDa}$ were completely biodegraded within 20 days (including a lag-phase of up to 5 days), test durations of 45 days and 65 days (including a lag-phase of approx. 22 days) were needed for complete biodegradation of PEGs with an MW of 26.6 and $57.8 \mathrm{kDa}$, respectively.

Most results of inherent biodegradability tests indicate DOC removal rates $>70 \%$ for PEGs with MWs up to $20 \mathrm{kDa}$ (Additional file 1: Table S5), i.e., the PEGs are likely to have a potential for degradation in well-operated WWTPs [77]. Note that in cases where only DOC removal rates are reported, adsorption processes may have contributed to the observed removal (see [78]). In a $50-\mathrm{d} \mathrm{CO}$ production test, mineralisation rates of $>80 \%$ $(1,3.4$, and $8 \mathrm{kDa})$ and $40 \%(20 \mathrm{kDa})$ were obtained [79]. Activated sludge from a previous semi-continuous activated sludge test with the same PEG was used as inoculum.

Several batch experiments with adapted and nonadapted activated sludge also provide evidence for primary biodegradation and mineralisation of PEGs under aerobic and anaerobic conditions (Table S5). In a continuous-flow model WWTP, $52 \%$ of the added ${ }^{14} \mathrm{C}$-labelled PEG (400 Da) was mineralised within $3 \mathrm{~d}$ [57]. According to information from safety data sheets, PEGs with MWs of 1.5 and $8 \mathrm{kDa}$ were effectively removed from the wastewater in model WWTPs (Table S5). Lara-Martín et al. [80] measured the concentrations of PEGs (MW: n.i.) in influent $(36-39 \mu \mathrm{g} / \mathrm{L})$ and effluent $(1.2-1.6 \mu \mathrm{g} / \mathrm{L})$ of a North American WWTP, and derived a removal rate of $96-97 \%$. In this context, it should be noted that PEGs are the main degradation products of alcohol ethoxylates and can, thus, be formed during the sewage treatment process [81-83].

Evidence for biodegradation in river water is available for PEG (300 Da): a primary biodegradation rate of $99 \%$ within 14 days was determined in a river water die-away test [84]. In artificial seawater inoculated with microorganisms obtained from filters of a seawater aquarium, PEGs with MWs up to $2 \mathrm{kDa}$ were completely degraded (DOC removal $>90 \%$ ) within 37 days, whereas PEGs with a MW of 4.5 and $7.4 \mathrm{kDa}$ needed 100 and 130 days, respectively, for complete biodegradation. At higher MW, PEGs were only partly degraded (DOC removal: $80 \%$ at MW of $10.3 \mathrm{kDa}$ and $40 \%$ at MW of $14.6 \mathrm{kDa}$ ) within 180 days. PEGs with MWs of 26.6 and $57.8 \mathrm{kDa}$ showed no biodegradation within 135 days [71]. Traverso-Soto et al. [85] investigated primary degradation of PEG (400 Da) in an anaerobic marine water/sediment system. They derived a half-life of 18 days and a primary degradation rate of $93 \%$ after 169 days.

Polymers that were removed from wastewater with the sludge may reach the environment when sewage sludge is applied to land. Only few information is available on biodegradation of PEGs in soil. Abdalla et al. [86] evaluated biodegradation of ${ }^{14} \mathrm{C}$-labelled PEG $(4 \mathrm{kDa})$ in three tropical soils. Within $70 \mathrm{~d}$, mineralisation $\left({ }^{14} \mathrm{CO}_{2}\right.$ production $)$ rates were $5-10 \%$, i.e., biodegradation was relatively slow.

Homo- and copolymers of acrylic acid In general, large addition polymers with carbon-to-carbon backbones, such as the considered AA-P\&CoPs, biodegrade very slowly [33, 87]. In ready biodegradability (modified MITI and closed bottle) tests, biodegradation rates of P-AAs (MW: n.i.) were generally below $20 \%$. It was assumed that only low MW material is degraded in these tests $[58,61]$. Methacrylic acid-ethyl acrylate copolymers (MAEACoP; $500 \mathrm{kDa}$ ) and acrylamide-acrylic acid copolymers (AAmAA-CoPs, $10,000 \mathrm{kDa}$ ) were also classified as not readily biodegradable $[88,89]$.

With regard to inherent biodegradability, results from semi-continuous activated sludge (SCAS) tests are available for P-AAs $(1-215 \mathrm{kDa})$ that were often tested at relatively high concentrations (e.g., $20 \mathrm{mg} / \mathrm{L}$; Additional 
file 1: Table S6). Overall removal rates are dependent on MW, first decreasing from $45 \%(1 \mathrm{kDa})$ to approximately $20 \%(2-3.4 \mathrm{kDa})$ and then increasing to $48 \%(23 \mathrm{kDa})$ and $95 \%$ (152 and $215 \mathrm{kDa})$ during 7 days [18, 19, 48]. Mineralisation of P-AA $(4.5 \mathrm{kDa})$ was studied in SCAS tests with adapted sludge coupled with $\mathrm{CO}_{2}$ production tests. Mineralisation rates of $8 \%(10-20 \mathrm{mg} / \mathrm{L}, 28$ days) and $16 \%(1 \mathrm{mg} / \mathrm{L}, 45$ days $)$ were derived [48]. To analyse the mechanisms of removal of P-AAs $(4.5 \mathrm{kDa})$ from wastewater, Freeman and Bender [48] conducted batch experiments (Additional file 1: Table S6). After addition of P-AAs (approx. $1 \mathrm{mg} / \mathrm{L}$ ) to a suspension of autoclaved sewage sludge in distilled water, $85 \%$ of the polymers were removed from the water. The authors concluded that adsorption onto sewage sludge was the most relevant removal process. Thus, overall removal of P-AAs in SCAS tests can be attributed to biodegradation being relevant at low MW (up to $1-2 \mathrm{kDa}$ ), and adsorption/ precipitation being most relevant at higher MW (see also $[18,58])$.

In Zahn-Wellens tests, low overall removal rates $<10 \%$ (based on DOC reduction) were recorded for P-AAs (15 kDa [19]) and MAEA-CoP (500 kDa [89]).

Several WWTP simulation studies are available for P-AAs. As in inherent biodegradation tests, removal from the water is due to biodegradation (low MW P-AAs) and adsorption/precipitation (higher MW P-AAs [18, 58]). In $\mathrm{CO}_{2}$ evolution tests with domestic activated sludge, biodegradation (mineralisation) of ${ }^{14} \mathrm{C}$-labelled P-AAs within $90 \mathrm{~d}$ decreased from $43 \%(1 \mathrm{kDa})$ to $19 \%(2 \mathrm{kDa})$ and $17 \%(10 \mathrm{kDa}[18,19])$. The overall removal rates tend to increase with increasing MW (see Additional file 1: Table S6 and [58]), but variation between the results of different studies is high. For instance, overall removal rates of $16-81 \%$ were reported for P-AAs with an MW of $4.5 \mathrm{kDa}$ (Additional file 1: Table S6, $[18,19,48]$ ). Interpretation of the data is hampered by the fact that, in many cases, relevant information, such as the polymer concentration, the suspended solid concentration, and the study duration, is not reported. In addition, different biodegradation rates can be caused by differences in the (not reported) MW distribution of polymers [33]. Generally, higher removal rates were obtained in tests with lower polymer concentrations [18]. For example, overall removal of P-AAs $(4.5 \mathrm{kDa})$ was $75-76 \%$ at $1 \mathrm{mg} / \mathrm{L}$, $27 \%$ at $3 \mathrm{mg} / \mathrm{L}$ and $16 \%$ at $30 \mathrm{mg} / \mathrm{L}[18,19]$. Freeman and Bender [48] measured removal rates of $81 \%(1 \mathrm{mg} / \mathrm{L})$, $75 \%(3 \mathrm{mg} / \mathrm{L})$, and $62 \%(10 \mathrm{mg} / \mathrm{L})$ for P-AA $(4.5 \mathrm{kDa})$ in laboratory-scale continuous activated sludge (CAS) tests using inocula from a WWTP treating municipal and light industrial wastewater (Table S6). They assumed that the decrease of removal rates with increasing polymer concentration is a result of the limited number of adsorption sites on the sewage sludge and point out that removal rates at concentrations likely to occur in WWTPs (generally $<1 \mathrm{mg} / \mathrm{L}$ ) may be underestimated in experiments with higher polymer concentrations. For P-AA with an MW of $78 \mathrm{kDa}$, an overall removal rate of $78 \%$ was determined in an activated sludge simulation test [18].

Tertiary treatment of wastewater with ferric chloride $\left(\mathrm{FeCl}_{3}\right)$ was shown to lead to an effective removal of P-AAs by precipitation. Removal rates $>90 \%$ were obtained in a model sewage treatment plant (MW: $4.5 \mathrm{kDa}[18])$ and in a CAS test (MW: n.i. $[48,60])$.

For P-AAs with an MW of $2000-4000 \mathrm{kDa}$ as used in cosmetics, experimental data on removal during wastewater treatment are lacking. Based on the evaluated data, they are unlikely to be biodegraded to a significant extent in WWTPs. Yet, given that adsorption/precipitation processes increase with MW, an effective removal can be assumed, especially in the presence of tertiary treatment with $\mathrm{FeCl}_{3}$.

Similarly, no experimental data on removal during wastewater treatment were identified for the considered copolymers of acrylic acid. However, high removal rates can be assumed due to complexation with divalent and polyvalent cations and sorption to activated sludge. For anionic polyacrylamide-based flocculants used in WWTPs, it was estimated that approx. $95 \%$ of the polymers are removed from the water during the flocculation step, while approx. 5\% remain dissolved and are discharged with the WWTP effluent [90].

Biodegradation in surface water was investigated with ${ }^{14} \mathrm{C}$-labelled P-AAs in river water die-away tests. During the test period of 135 days, mineralisation $\left({ }^{14} \mathrm{CO}_{2}\right.$ evolution) was incomplete and decreased with increasing MW (20\% at $1 \mathrm{kDa}, 10 \%$ at $2 \mathrm{kDa}$ and $7 \%$ at $10 \mathrm{kDa})$. Considerably higher mineralisation rates were measured when using pre-adapted river water $(63 \%$ at $1 \mathrm{kDa}, 15 \%$ at $10 \mathrm{kDa})$ or a mixture of river water and sediment $(58 \%$ at $1 \mathrm{kDa}, 37 \%$ at $2 \mathrm{kDa}$, and $12 \%$ at $10 \mathrm{kDa}[18,19])$. The latter might be due to a higher biomass introduced into the system with the sediment. For the considered copolymers of acrylic acid, no results of biodegradation studies in surface water were identified.

In sludge-treated soil, biodegradation of ${ }^{14} \mathrm{C}$-labelled P-AAs was slow: during an incubation period of 165 days, mineralisation rates of $35 \%$ (1 kDa), 11\% (2 kDa), and $5 \%(10 \mathrm{kDa})$ were obtained. For P-AA with an MW of $4.5 \mathrm{kDa}$, a mineralisation rate of $6 \%$ was determined after 81 days $[18,19]$. Similarly, biodegradation of ${ }^{13} \mathrm{C}$-labelled P-AAs in agricultural soil was limited. Bai et al. [72] derived mineralisation rates of $1.85 \%\left(\mathrm{MW}_{\mathrm{n}}: 219.5 \mathrm{kDa}\right)$ and $0.91 \%\left(\mathrm{MW}_{\mathrm{n}}: 530.4 \mathrm{kDa}\right)$ within 149 days. Based on the ratios of (a) the chain lengths and (b) the mineralisation rates of both polymers, they concluded that 
biodegradation mainly occurs at the terminal sites of the polymers.

Wolter et al. [91] investigated biodegradation of ${ }^{14} \mathrm{C}$-labelled AAmAA-CoP (MW: n.i.; 51\% water-soluble and $49 \%$ cross-linked, not water-soluble constituents) in soil. Tube $(T)$ and flask $(F)$ reactors containing the polymers, agricultural soil and, partly, ground wheat straw and white or brown rot fungi were exposed for 22 weeks (Table S6). In soil without any additions, mineralisation rates were $1.1 \%(T)$ and $2.2 \%(F)$. Mineralisation rates were increased when ground wheat straw $(T: 1.6 \%, F$ : $3.1 \%$ ) and additionally white rot fungus Pleurotus ostreatus (T: 5.3, F: 8.8\%) had been added. In the reactors with $P$. ostreatus, the percentage of water-soluble polymers was increased as compared to soil without additions. Wolter et al. [91] assumed that the ligninolytic exoenzymes that are released by $P$. ostreatus led to a fragmentation of the polymer and made it more accessible to further degradation.

Biodegradation of AAmAA-CoP (Superfloc 836A, $12,000 \mathrm{kDa}$ ) was also investigated under field conditions. The copolymers were applied to agricultural soil and degradation was studied after 6 and 12 years using stable isotope $\left({ }^{13} \mathrm{C}\right)$ ratios. A mean degradation rate of $9.8 \%$ per year was derived [92]. A very similar degradation rate was obtained for a polyacrylamide copolymer, which is not among the set of polymers considered in the present evaluation: Hennecke et al. [46] investigated the degradation of a ${ }^{14} \mathrm{C}$-labeled cationic polyacrylamide copolymer (6000 kDa, $30 \mathrm{~mol} \%$ acrylamide) in sludge-treated soil in an outdoor lysimeter study. Throughout the 3-year test duration, MW of the polymer decreased significantly due to cleavage of the carbon backbone. A mineralisation rate of $22.5 \%$ within 2 years was derived. In this study, the formation of non-extractable residues (NERs) was also investigated. Throughout the test duration, levels of NERs were around $10 \%$ of the applied radioactivity. As noted by Hennecke et al. [46], the amount of NERs was probably underestimated, because a matrix-destructive extraction method was used.

Polyquaterniums Only very limited information was identified on biodegradation of the considered PQs. Most data originate from product safety data sheets for PQ grades used in cosmetics (Additional file 1: Table S7). PQ-6 (>10 kDa [31]), PQ-10 (approx. $400 \mathrm{kDa}$ and 30,000 kDa $[93,94])$, and PQ-16 (40-400 kDa [95-98]) are not readily biodegradable. For PQ-16 (100 and $400 \mathrm{kDa}$ ), mineralisation rates within 28 days were below $10 \%$ of the theoretical oxygen demand $[95,97]$.

According to ECCC and HC [31], PQ-6 (>10 kDa) was found to be not inherently biodegradable. Inherent biodegradability of PQ-7 and PQ-16 was studied in
Zahn-Wellens tests: PQ-7 (MW: n.i.) showed 30-50\% biodegradation [99], and for PQ-16, DOC removal rates of $20-70 \%$ (40 and $80 \mathrm{kDa}[96,98])$ and $40-50 \%(100 \mathrm{kDa}$ [97]) were obtained. No data were identified for PQ-10. More information is required to draw conclusions on inherent biodegradability of PQ-7, -10 and -16 .

Experimental data on removal of PQ-6, -7, -10, and -16 during wastewater treatment are lacking. However, strong sorption of the positively charged PQs to the negatively charged sewage sludge is likely to lead to an effective removal from wastewater. This is substantiated by the fact that PQ-6 is used in wastewater treatment, where it efficiently removes suspended material from the water phase $[32,100]$.

No data were identified on biodegradation of the considered PQs in surface water, sediments, and soil. In view of their sorptive properties, especially biodegradation of the PQs in sediments and (sludge-amended) soils should be evaluated.

\section{Mobility in the environment}

Due to their sorption behaviour, the considered polymers reach the terrestrial environment when sewage sludge is applied to land. While the amounts of sewage sludge applied to agricultural land have decreased strongly in some European countries (e.g., The Netherlands, Switzerland, and Germany), agricultural use of sewage sludge is still common in other countries (e.g., Portugal and Spain [101]). Mobility of ${ }^{14} \mathrm{C}$-labelled P-AA with a mean MW of $4.5 \mathrm{kDa}$ in sandy soil was evaluated in a lysimeter study with a duration of 10 weeks ([18], Additional file 1: Table S8). While $10 \%$ of the applied polymers were eluted with the percolate water, most polymers remained in the top $10-15 \mathrm{~mm}$ of the soil column. The eluted mobile fraction was presumed to consist of low MW material [18, $58,61]$. Similar or higher retention rates were recorded in soil column mobility studies, in which P-AA $(4.5 \mathrm{kDa})$ was applied to sand and loam columns: $8 \%$ of the applied polymers were eluted from the sand columns and only $0.5 \%$ from the loam columns ([102], Additional file 1: Table S8). Since sorption increases with MW, it can be assumed that P-AAs with an MW of 2000-4000 kDa as used in cosmetics are likely to remain in the sludge or in the upper soil layer when applied with sewage sludge to soil. Desorption and elution to surface water or groundwater are unlikely unless they degrade to smaller, more mobile fragments.

No experimental data on mobility in soil were identified for the other considered polymers. However, the results of the abovementioned outdoor lysimeter study with a ${ }^{14} \mathrm{C}$-labeled cationic polyacrylamide copolymer (6000 kDa, $30 \mathrm{~mol} \%$ acrylamide) also indicate a very low polymer mobility in sludge-treated soil: 3 years after 
polymer application, $93.5 \%$ of the total radioactivity was detected in the upper $10 \mathrm{~cm}$ of the soil columns [46]. Due to their sorption behaviour (section "Sorption and complexation") and considering the data discussed above, a low mobility in sludge and soil is assumed for higher MW PEGs, copolymers of acrylic acid, and, especially, PQs. In their screening environmental risk assessment of PQ-6 $(>10 \mathrm{kDa})$, ECCC \& $\mathrm{HC}$ [31] also concluded that the polymer is expected to strongly sorb to soil with limited partitioning to pore water. Similarly, Guezennec et al. [24] point out that for polyacrylamide-based flocculants (including AAmAA-CoPs), mobility in soil and leaching to groundwater are limited by their strong sorption to sludge and soil and low desorption rates.

Polymers that are not removed from wastewater are discharged with the WWTP effluent into surface waters. Due to their sorptive properties, it can be expected that they are discharged in a sorbed form (sorbed to the residual organic material in the WWTP effluent [7]). In the aquatic environment, they are assumed to rapidly partition to the sediment (see also [31]). This assumption should be verified in experimental studies with representative polymers, given that apart from few $K_{\mathrm{d}}$ and $K_{\mathrm{OC}}$ values (Additional file 1: Table S4), experimental data on the partitioning behaviour and mobility of the considered polymers in the aquatic environment are not publicly available.

\section{Uptake and bioaccumulation of water-soluble synthetic organic polymers}

Experimental data on uptake and possible bioaccumulation are lacking for the here considered polymers. In the following, their bioaccumulation potential is therefore discussed based on theoretical considerations and information available for other polymers and non-polymeric substances. Uptake by passive diffusion is the most relevant transport process, especially for uptake of substances from the surrounding aqueous medium [103], but also for uptake via ingestion. Substances have to cross diffusion barriers, such as mucous and respiratory, dermal or intestinal surfaces [103, 104]. Lipophilicity strongly favours transport across membranes [105], while ionizable hydrophilic chemicals have a low potential to cross biological membranes by passive diffusion and usually depend on active transport by ion pumps or ion channels [106]. Yet, such active transport mechanisms have so far not been described to be effective for polymers [19].

Molecular size is considered as the main factor limiting the uptake of polymers through membranes and tissue barriers into biota $[9,11,87]$. For polymers with an $\mathrm{MW}_{\mathrm{n}}$ above $1000 \mathrm{Da}$, absorption by aquatic organisms through respiratory membranes has been considered unlikely
$[7,41]$. For organic chemicals in general, there appears to be no clear size-related cut-off for bioconcentration [103, 107-109]. However, substances with an MW above $600 \mathrm{Da}$ tend to have bioconcentration factors $<1000$ [103], i.e., clearly below the threshold value of 2000 for classifying a substance as bioaccumulative specified in Annex XIII of the REACH regulation [110]. The MWs of the AA-P\&CoPs, the PQs, and the higher MW PEGs considered in the present evaluation are clearly (often by orders of magnitude) above 600-1000 Da (Additional file 1: Tables S1-S3). These high MWs are very likely to hamper uptake of these polymers through biological membranes/tissue barriers into biota. Since PEGs with MWs up to 4-14.6 kDa are readily biodegradable (section "Biodegradation and removal in WWTPs"), there is no concern regarding their bioaccumulation.

Binding of substances to, e.g., dissolved organic material reduces their bioavailability to aquatic organisms $[103,104]$. Accordingly, sorption and complexation of the considered polymers (section "Sorption and complexation") are further factors limiting their uptake by diffusion from the surrounding aqueous medium and, thus, their bioconcentration (see also $[18,19,61]$ ).

The uptake of polymers, which are bound to, e.g., suspended solids, sediment, or soil, by ingestion deserves further attention [111]. For mammals, substances with MWs $>1000 \mathrm{Da}$ [112] or "in the 1000s" [113] are considered too large to cross the intestinal membranes. However, the upper size limits for transfer across intestinal membranes should be investigated for environmental organisms from different taxonomic groups. It should also be verified if gastrointestinal processing may lead to the cleavage of polymers into smaller fragments.

\section{Environmental effects of water-soluble synthetic organic polymers}

A simple classification scheme was used to categorise the aquatic toxicity of the considered polymers (Table 2). Most compiled effect concentrations are based on nominal polymer concentrations due to missing analytical verification of actual test concentrations. This is because sufficiently specific methods for chemical analysis are often lacking [11, 111, 114-117].

\section{Aquatic organisms}

Polyethylene glycols Most non-ionic polymers are considered of low concern for aquatic organisms [7, 12, 42, 125]. This is corroborated by the ecotoxicity data compiled for the considered PEGs (Additional file 1: Table S9). Based on data from safety data sheets, PEGs with MWs ranging from $200 \mathrm{Da}$ to $400,000 \mathrm{kDa}$ are categorised as not toxic to aquatic microorganisms. In algal tests, $\mathrm{EC}_{50}$ and $\mathrm{IC}_{50}$ values $>100 \mathrm{mg} / \mathrm{L}$ (i.e., the highest concentration that 
Table 2 Classification scheme for acute and chronic aquatic ecotoxicity of the considered polymers (based on [118, 119] a , adapted)

\begin{tabular}{lllll}
\hline & Ecotoxicity & & & Moderate \\
\cline { 2 - 4 } & No & Low & $>1$ to $\leq 10 \mathrm{mg} / \mathrm{L}$ & High \\
\hline Acute $\mathrm{LC}_{50}$ or EC & $>100 \mathrm{mg} / \mathrm{L}^{\mathrm{b}}$ & $>10$ to $\leq 100 \mathrm{mg} / \mathrm{L}$ & $>0.1$ to $\leq 1 \mathrm{mg} / \mathrm{L}$ & $\leq 1 \mathrm{mg} / \mathrm{L}$ \\
Chronic NOEC or EC & $>10 \mathrm{mg} / \mathrm{L}^{\mathrm{c}}$ & $>1$ to $\leq 10 \mathrm{mg} / \mathrm{L}$ & $\leq 0.1 \mathrm{mg} / \mathrm{L}$ \\
\hline
\end{tabular}

a The classification schemes of Wagner et al. [118] and UN [119] were developed for aquatic toxicity data for algae, crustaceans, and fish

b Highest concentration that has to be tested according to OECD test guidelines 201 [120], 202 [121], and 203 [122]

c Highest concentration that has to be tested according to OECD test guidelines 211 [123] and 210 [124]

has to be tested in standard tests, see Table 2) were derived for PEGs with MWs ranging from $200 \mathrm{Da}$ to approx. $6-8 \mathrm{kDa}$, indicating a lack of toxicity [126-130]. Chronic effect concentrations for algae are only available for PEG with an MW of approx. 6-8 kDa, which showed no toxicity to Chlorella sp. $[129,130]$. Acute toxicity of PEGs to crustaceans (Daphnia magna or Daphnia sp.) was in most cases absent $\left(\mathrm{EC}_{50}>100 \mathrm{mg} / \mathrm{L}\right.$; Table S9), while one test with PEG with an MW of $600 \mathrm{Da}$ indicates low toxicity $\left(\mathrm{EC}_{50}: 53 \mathrm{mg} / \mathrm{L}\right.$ [131]). With regard to chronic toxicity to crustaceans, only a single test was identified: a reproduction test with the cladoceran Moinodaphnia macleayi. In this test, PEG (approx. 6-8 kDa) was non-toxic (NOEC: $750 \mathrm{mg} / \mathrm{L}[129,130])$. With $\mathrm{LC}_{50}$ values $>100 \mathrm{mg} / \mathrm{L}$, PEGs (200 Da-400,000 kDa) were shown to lack acute toxicity to a number of fish species (Table S9). In a prolonged acute fish test, concentrations of 5 and $10 \mathrm{mg} / \mathrm{L}$ of PEG (400 Da) did not affect survival of carp (Cyprinus carpio) during a 21-day exposure [132]. Data on chronic effects of PEGs on fish were not available.

Homo- and copolymers of acrylic acid Numerous ecotoxicity data were identified for P-AAs with MWs ranging from approx. 1 to $215 \mathrm{kDa}$. However, all data originate from confidential studies with few experimental details available (Additional file 1: Table S10). For the considered copolymers of acrylic acid (MAEA-CoP and AAmAA$\mathrm{CoP})$, the amount of ecotoxicity data linked to sufficiently specific information on polymer identity was relatively limited. Since anionic polycarboxylates form poorly soluble complexes with divalent and polyvalent cations (section "Sorption and complexation"), their aquatic toxicity is influenced by water hardness $[7,87]$. However, details on water hardness in the ecotoxicity tests are often not reported, which hampers a detailed analysis of test results.

With effect concentrations $>100 \mathrm{mg} / \mathrm{L}, \quad$ P-AAs (1-15 kDa) were categorised as non-toxic in activated sludge respiration inhibition tests $[19,48,133]$, and the performance of model WWTPs was not affected by P-AA concentrations up to $30 \mathrm{mg} / \mathrm{L}(4.5 \mathrm{kDa})$ or $50 \mathrm{mg} / \mathrm{L}$
(78 kDa [18]). The considered copolymers of acrylic acid, MAEA-CoP (approx. $500 \mathrm{kDa}$ ), and AAmAA-CoP $(10,000 \mathrm{kDa})$ also lacked toxicity to activated sludge and Pseudomonas putida, respectively $([89,129]$, see Additional file 1: Table S10).

In algal growth tests, $\mathrm{EC}_{50}$ values for P-AAs (1.4$78 \mathrm{kDa}$ ) range from 3.13 to $>100 \mathrm{mg} / \mathrm{L}$ and chronic effect concentrations from 0.5 to $>100 \mathrm{mg} / \mathrm{L}$ (Additional file 1: Table S10). Two of the lowest $\mathrm{EC}_{50}$ values (5.5 and $7.6 \mathrm{mg} / \mathrm{L}$ ) and the two lowest chronic effect concentrations $(0.5$ and $0.54 \mathrm{mg} / \mathrm{L})$ were reported for P-AAs with a very high oligomer content (40 and $49 \%$ [7]) that has most likely contributed to the toxicity. Notably, highest toxicity was recorded in standard algal growth media with a low water hardness $\left(10-24 \mathrm{mg} / \mathrm{L}\right.$ as $\left.\mathrm{CaCO}_{3}\right)$. Based on the few available data, MAEA-CoP (approx. $500 \mathrm{kDa}$ ) and AAmAA-CoP $(10,000 \mathrm{kDa})$ had no acute (both copolymers) and no chronic toxicity (AAmAA-CoP, tested in soft water) to algae (Additional file 1: Table S10). Based on their evaluation of data submitted to the US EPA, Boethling and Nabholz [7] concluded that P-AAs and other poly(aliphatic acids) have an indirect toxic effect on algae, which is caused by the chelation of cationic nutrients $\left(\mathrm{Ca}^{2+}, \mathrm{Mg}^{2+}\right.$, and $\left.\mathrm{Fe}^{3+}\right)$. Chelation strength was found to depend on the distance between carboxylic acid groups: P-AAs, with carboxylic acid groups on every other carbon of their backbone, had higher algal toxicities than poly(aliphatic acids) with a lower or higher distance between their carboxylic acid groups as, e.g., MAEA-CoP and AAmAA-CoP (Additional file 1: Table S2).

The evaluated studies indicate that P-AAs $(1-78 \mathrm{kDa})$, MAEA-CoP (approx. $500 \mathrm{kDa}$ ), and AAmAA-CoP $(10,000-20,000 \mathrm{kDa})$ have no acute effects on crustaceans (Additional file 1: Table S10). This is in line with the finding of Boethling and Nabholz [7] that at $\mathrm{pH}$ values around 7, poly(aliphatic acids) are usually not acutely toxic to daphnids. Chronic toxicity data for D. magna are available for P-AAs with MWs of 4.5 and $78 \mathrm{kDa}$. For P-AA (4.5 kDa), NOECs range from $5.6 \mathrm{mg} / \mathrm{L}$ to $>100 \mathrm{mg} / \mathrm{L}$ (Additional file 1: Table S10). Strongest 
effects were observed under conditions where precipitation occurred $[18,19,58]$. An NOEC of $450 \mathrm{mg} / \mathrm{L}$ was derived for the soluble state of P-AA $(4.5 \mathrm{kDa})$ and an NOEC of $12 \mathrm{mg} / \mathrm{L}$ for the precipitation product $[18,19]$. For P-AA (78 kDa), NOECs $>100 \mathrm{mg} / \mathrm{L}$ indicate a lack of chronic toxicity to D. magna $[18,19])$. No information on water hardness is provided for these data. For the considered copolymers of acrylic acid, only a single chronic crustacean test was identified. An NOEC of $1 \mathrm{mg} / \mathrm{L}$ was derived for the effects of AAmAA-CoP $(10,000 \mathrm{kDa})$ on reproduction of the cladoceran $M$. macleayi in very soft $(10-22 \mu \mathrm{S} / \mathrm{cm})$ water $[129,130]$. The chelation of $\mathrm{Ca}^{2+}$ by AAmAA-CoP might have contributed to the toxicity to $M$. macleayi, given that crustaceans need $\mathrm{Ca}^{2+}$ for growth and moulting [134].

In short-term tests with other freshwater invertebrates, AAmAA-CoPs lacked toxicity. The polymers (MWs between 9000 and 17,000 kDa) had no acute effects on larvae and juveniles of four mussel species exposed in hard water [135]. Effects $(10,000 \mathrm{kDa})$ on the population growth rate of the polyp Hydra viridissima were only recorded at high concentrations (NOEC $>10 \mathrm{mg} / \mathrm{L}$, $\mathrm{IC}_{50}>100 \mathrm{mg} / \mathrm{L}$ ). They were mainly attributed to the viscosity of the polymer solutions, which appeared to reduce the probability of encounter between polyps and their food. Results of an additional experiment with a flocculant formulation containing AAmAA-CoP $(10,000 \mathrm{kDa})$ and a PEG showed that effects were mitigated when it was ensured that each polyp received sufficient food $[129,130]$.

With $\mathrm{LC}_{50}$ values $>100 \mathrm{mg} / \mathrm{L}$, P-AAs $(1-78 \mathrm{kDa})$, MAEA-CoPs (approx. $500 \mathrm{kDa}$ ), and AAmAA-CoPs $(10,000-20,000 \mathrm{kDa})$ had no acute toxicity to fish (Additional file 1: Table S10). Results of fish early life stage tests with zebrafish (Danio rerio) and fathead minnows (Pimephales promelas) showed that P-AA (4.5 kDa) lacks chronic fish toxicity $[18,48,58]$. For AAmAA-CoP $(10,000-20,000 \mathrm{kDa})$, no effects on survival and growth were recorded in a 30-d test with lake trout (Salvelinus namaycush) fry. At very high concentrations of AAmAA$\mathrm{CoP}(\geq 150 \mathrm{mg} / \mathrm{L})$, where viscosity of the test solutions was visibly increased, swimming behaviour was reduced and respiration was laboured [114]. In lake trout fry exposed for $96 \mathrm{~h}$ or $30 \mathrm{~d}$ to AAmAA-CoP in moderately hard water $\left(76 \mathrm{mg} / \mathrm{L}\right.$ as $\left.\mathrm{CaCO}_{3}\right)$, effects on gill histology were only detected at concentrations $\geq 300 \mathrm{mg} / \mathrm{L}$ and $\geq 150 \mathrm{mg} / \mathrm{L}$, respectively [114]. The surfaces of fish gills are negatively charged [136]. In the presence of divalent cations, anionic polycarboxylates can sorb to negatively charged surfaces (section "Sorption and complexation"). The histopathological changes are probably a response to respiratory stress caused by sorption of polymers to the gill surface.
At higher water hardness, algal toxicity of poly(aliphatic acids) was found to be reduced [7, 87]. In addition, aquatic toxicity of anionic polymers is generally mitigated by their sorption to suspended particles and sediments [53]. Anionic polycarboxylates, which are released with WWTP effluents to surface water, are expected to have already bound to divalent and polyvalent cations and sorbed to suspended solids (section "Mobility in the environment"). Effects on aquatic organisms due to a chelation of cations are therefore unlikely to occur in the environment (see also [18]).

Polyquaterniums In laboratory tests, water-soluble cationic polymers generally have a higher toxicity to aquatic organisms than anionic and non-ionic polymers. Their effects are thought to result from electrostatic interactions with negatively charged biological membranes, including bacterial membranes, the outer cell wall of algae, and respiratory membranes such as the gills $[41,117,125$, 137-139]. Aquatic toxicity of cationic polymers was often found to increase with increasing charge density, especially in water with a low OC content $[7,12,42,117]$.

For the four considered PQs, a considerable amount of ecotoxicity data was identified. However, for many data, only limited information on experimental details (including the OC content of the test water) is available, a fact that partly hampers a detailed analysis of test results.

In activated sludge respiration inhibition tests, PQ-10 $\left(E_{50}>1000 \mathrm{mg} / \mathrm{L}\right)$ and PQ-16 $\left(\mathrm{EC}_{20}>100 \mathrm{mg} / \mathrm{L}\right)$ were non-toxic. Lower effect concentrations (PQ-7: $\mathrm{EC}_{0}$ between 10 and $100 \mathrm{mg} / \mathrm{L}$; PQ-16: $\mathrm{EC}_{10}$ values of 0.68 and $0.92 \mathrm{mg} / \mathrm{L}$ ) were obtained in cell multiplication inhibition tests with P. putida (Additional file 1: Table S11). Differences between the results obtained in these two tests systems are most likely related to the fact that PQs strongly sorb to sewage sludge. The activated sludge content $(1.5 \mathrm{~g} / \mathrm{L}$ according to [140]) is assumed to limit the bioavailability of PQs and to mitigate their toxicity in activated sludge respiration inhibition tests.

Based on the compiled data, the PQs have a moderate or, in most cases, high toxicity to algae: $\mathrm{EC}_{50}$ values were 0.03 and $0.16 \mathrm{mg} / \mathrm{L}$ for PQ-6, 0.04-0.05 mg/L for PQ-10 and between 0.1 and $1.10 \mathrm{mg} / \mathrm{L}$ for PQ-16 [31, 66, 96-98]. For three PQ-7 grades, $\mathrm{EC}_{20}$ values of 0.06 to $0.32 \mathrm{mg} / \mathrm{L}$ were determined in tests with Raphidocelis subcapitata with higher toxicity at higher charge density and lower water hardness ([117], Additional file 1: Table S11). NOEC values were $0.066 \mathrm{mg} / \mathrm{L}$ for PQ-6 [31], and 0.002 and $0.013 \mathrm{mg} / \mathrm{L}$ for PQ-10 [66]. Generally, algae were expected to be very sensitive to PQs and other cationic polymers [41, 141, 142]. Effects were attributed to a disruption of the negatively charged outer cell wall $[117,139]$. At a sufficiently high concentration, PQs can 
lead to a flocculation of the algae [32, 137, 143-145]. In this context, it is of note that some PQs are used as algicides/swimming pool clarifiers [146]. Due to their flocculating properties, PQs may prevent a homogenous distribution of algae in the test medium [147, 148], a fact that may hamper evaluation of algal tests.

Acute toxicity to crustaceans (D. magna, Daphnia pulex, C. dubia) is absent to high depending on the polymer (i.e., PQ-6, $-7,-10$ or -16 ), its charge density and $\mathrm{MW}$, and water hardness. For the homopolymer PQ-6 (6.2 meq/g), $\mathrm{LC}_{50}$ values increase with $\mathrm{MW}$, ranging from $0.20 \mathrm{mg} / \mathrm{L}(25 \mathrm{kDa}$ [149]) to $2.00 \mathrm{mg} / \mathrm{L}$ (200 kDa [150]). For three PQ-7 grades, $\mathrm{EC}_{50}$ values range from 0.4 to $10.3 \mathrm{mg} / \mathrm{L}$, increasing at lower charge density and higher water hardness [117]. For PQ-16, $\mathrm{EC}_{50}$ values increase with increasing $\mathrm{MW}$ and decreasing charge density from $0.1-1 \mathrm{mg} / \mathrm{L}$ (40 kDa, $6.1 \mathrm{meq} / \mathrm{g}$ [98]) to $31.5 \mathrm{mg} / \mathrm{L}$ (100 kDa, $2.0 \mathrm{meq} / \mathrm{g}$ [97]). Based on the available data, PQ-10 ( $\left.\mathrm{LC}_{50}: 34-669 \mathrm{mg} / \mathrm{L}\right)$ has a low or no toxicity to daphnids. As specific information on the charge density and MW is partly lacking or controversial (see Additional file 1: Table S11), an evaluation of the effects of these two parameters on toxicity of PQ-10 is not possible. Information on chronic toxicity to crustaceans is only available

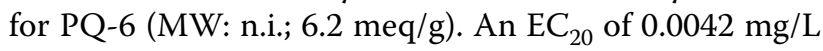
was derived in a $7-\mathrm{d}$ reproduction test with $C$. dubia, i.e., PQ-6 had a high toxicity to the daphnid [151]. Effects of cationic polymers on daphnids were attributed to binding of the polymers to the integument and appendages, resulting in an inhibition of swimming and feeding activity and an aggregation of the organisms (i.e., physical effects [149, 151-153]). Flocculation of the daphnids' food (algae) may have contributed to the chronic effects on daphnids.

Acute fish toxicities of the considered PQs also cover the whole range, from absent to high. For PQ-16, LC values increase with increasing $\mathrm{MW}$ and decreasing charge density from $0.1-1 \mathrm{mg} / \mathrm{L}(40 \mathrm{kDa}, 6.1 \mathrm{meq} / \mathrm{g}$ [98]) to $1-2.2 \mathrm{mg} / \mathrm{L}(100 \mathrm{kDa}, 2.0 \mathrm{meq} / \mathrm{g}$ [97]). For the other PQs, an evaluation of the effects of MW and charge density is hampered by the fact that information on these parameters is partly controversial (PQ-10) or lacking (Additional file 1: Table S11). Most $\mathrm{LC}_{50}$ values for PQ-6 (6.2 meq/g) range from $0.46 \mathrm{mg} / \mathrm{L}(25 \mathrm{kDa}$ [149]) to $2.08 \mathrm{mg} / \mathrm{L}$ (MW: n.i. [114]), while higher $\mathrm{LC}_{50}$ values $(10-100 \mathrm{mg} / \mathrm{L} ; \mathrm{MW}:$ n.i.) are reported in ECCC \& $\mathrm{HC}$ [31]. Based on the few identified data, PQ-7 (4,300$5,200 \mathrm{kDa}, 1.6 \mathrm{meq} / \mathrm{g})$ has a low fish toxicity $\left(\mathrm{LC}_{50}\right.$ : $10-100 \mathrm{mg} / \mathrm{L}$ [154]). For PQ-10, $\mathrm{LC}_{50}$ and $\mathrm{EC}_{50}$ values for loss of equilibrium range from $0.96 \mathrm{mg} / \mathrm{L}$ to $>100 \mathrm{mg} / \mathrm{L}$ $[66,155]$. Chronic fish toxicity data were only available for PQ-6 (MW n.i.). In a 30-d test with lake trout (S. namaycush) fry, a NOEC of $0.5 \mathrm{mg} / \mathrm{L}$ was derived for survival and a NOEC of $0.25 \mathrm{mg} / \mathrm{L}$ for the non-standard test endpoint startle response ([114], see Additional file 1: Table S11). Toxicity of cationic polymers to fish has mainly been attributed to their binding to the respiratory membranes of the gills and the resulting interference with oxygen exchange and ion regulation [31, 41, $42,114,125,137,156]$. In their studies with lake trout fry, Liber et al. [114] also evaluated potential effects of PQ-6 (MW n.i., $6.2 \mathrm{meq} / \mathrm{g}$ ) on gill histology. Acute (96 h) exposure of lake trout fry led to clear histopathological effects (see Additional file 1: Table S11), and hypoxia and impaired ionoregulation were considered as main causes for the observed toxicity of PQ-6. By contrast, no significant effects on gill histology were recorded after chronic (30 d) exposure to concentrations up to $1.0 \mathrm{mg} / \mathrm{L}$, possibly due to an adaptation of the fish to the respiratory/ ionoregulatory stress caused by the polymer.

In the presence of negatively charged DOC, suspended solids, and sediments, the aquatic toxicity of cationic polymers is strongly reduced as a consequence of sorption and charge neutralisation $[7,12,41,42,87,117,125$, $137,149,157]$. Such a reduction of toxicity was demonstrated for the acute effects of PQ-6 on daphnids and fish: Cary et al. [149] exposed D. magna and P. promelas for 48 and $96 \mathrm{~h}$, respectively, to PQ-6 (25 kDa, $6.2 \mathrm{meq} / \mathrm{g})$, either with or without (a) $50 \mathrm{mg} / \mathrm{L}$ of suspended solids or (b) $10 \mathrm{mg} / \mathrm{L}$ of DOC (see Additional file 1: Table S11). The presence of negatively charged suspended solids and DOC clearly reduced acute toxicity of PQ-6 to D. magna. Among the suspended solids, bentonite had the strongest mitigating effect (mitigation factor: 36), and among the DOC compounds, lignin (mitigation factor $>77$ ). A mitigation factor of 37 was derived for humic acid. In the fish tests, bentonite and all used DOC compounds clearly reduced the toxicity of PQ-6, although the mitigating effects were less strong than in the daphnid tests (mitigation factors $\leq 14$ ). Salinas et al. [117] investigated the effects of the addition of small amounts of humic acid (total organic carbon (TOC): $0.25,0.5$, and $1 \mathrm{mg} / \mathrm{L}$ ) on the toxicity of three PQ-7 grades on algae and daphnids at different levels of water hardness (Additional file 1: Table S11). In the presence of humic acids, toxicity was reduced by factors of 2-16 (algae) and 2-11 (daphnids). Although to a lower extent than humic acids, water hardness was also found to mitigate toxicity. This mitigation could be related to binding of $\mathrm{Ca}^{2+}$ and $\mathrm{Mg}^{2+}$ to the negatively charged surfaces of the test organisms, reducing the availability of binding sites for the polymers, or to effects of water hardness on the conformation of the polymer. Background TOC levels in the Daphnia test medium were found to range from 0.6 to $1.6 \mathrm{mg} / \mathrm{L}$. In view of this fact and the considerable influence of TOC and water hardness levels (which were both within test 
guideline limits) on toxicity, Salinas et al. [117] suggested a further standardisation of the test media used for aquatic toxicity testing of cationic polymers to improve reproducibility.

As mentioned before (section "Mobility in the environment"), cationic polymers, which reach the aquatic environment with WWTP effluents, are assumed to have already sorbed to suspended solids or DOC. This fact further reduces the probability of interactions between the polymers and the negatively charged surfaces of aquatic organisms and, consequently, toxic effects, in the receiving water. Hence, effect concentrations derived in standard ecotoxicity tests in water with a low TOC content $(<2 \mathrm{mg} / \mathrm{L}$ [158]) are likely to overestimate possible effects of cationic polymers released with wastewater effluents on aquatic organisms $[7,117,150]$.

\section{Sediment organisms}

For the considered polymers, only a single, acute watersediment toxicity test was identified. In this 96-h test with larvae of the non-biting midge Chironomus riparius, an $\mathrm{EC}_{0}>4500 \mathrm{mg} / \mathrm{kg} \mathrm{dw}$ was derived for P-AA (4.5 kDa), indicating no acute toxicity to chironomids $([18,19]$, see Additional file 1: Table S10). Chronic toxicity data for sediment organisms, which are required to characterise effects on sediment organisms [159], are lacking. Since uptake of the considered polymers into biota is limited, and toxicity in water-only tests is either low (PEGs) or mitigated by sorption to DOC (PQs) and particulate matter (AA-P\&CoPs, $\mathrm{PQs}$ ) and/or at higher water hardness (AA-P\&CoPs, PQ-7), no or a low toxicity to sediment organisms is expected. However, this should be verified for representative polymers in chronic water-sediment toxicity tests with benthic deposit feeders (e.g., $C$. riparius, the oligochaete Lumbriculus variegatus, and the crustacean Hyalella azteca) that will ingest polymers, which are bound to sediment particles.

\section{Terrestrial organisms}

Results from laboratory toxicity tests with soil organisms were only identified for P-AAs (few experimental details are available; Additional file 1: Table S10). All data demonstrate a lack of toxicity to terrestrial organisms: $\mathrm{EC}_{10}$ values $>2500 \mathrm{mg} / \mathrm{kg} \mathrm{dw}(4.5 \mathrm{kDa})$ were derived in 28-day nitrogen and carbon transformation tests, and NOECs of $225 \mathrm{mg} / \mathrm{kg}(4.5 \mathrm{kDa})$ and $1000 \mathrm{mg} / \mathrm{kg}(78 \mathrm{kDa})$ in chronic plant tests. In addition, P-AA concentrations up to $1000 \mathrm{mg} / \mathrm{kg}(4.5 \mathrm{kDa}, 78 \mathrm{kDa})$ had no acute effects on earthworms $[18,19]$. Due to limited uptake into biota and the fact that (aquatic) toxicity is low or reduced by binding to DOC and particulate material, no or a low toxicity to soil organisms is likely for the other polymers. This assumption should be verified for representative polymers using chronic toxicity tests with saprophagous organisms such as earthworms (e.g., Eisenia fetida), enchytraeids (e.g., Enchytraeus albidus), and isopods (e.g., Porcellio scaber), which will ingest polymers that are bound to soil particles.

\section{Conclusions}

A considerable number of data on the environmental fate and effects were identified for some of the selected water-soluble synthetic organic polymers, whereas data were more limited for others. Only few specific data were available regarding certain aspects, such as sorption and mobility in the aquatic and terrestrial environment. For many studies, information on the characteristics of the tested polymers and on experimental details was not publicly available. Accordingly, data reliability often had to be classified as 'not assignable'. However, the compiled information was sufficient for deriving first conclusions and general trends regarding the environmental fate of the selected polymers and their effects on aquatic organisms (see Fig. 1).

Generally, water solubility, charge, MW, and the percentage of low MW constituents are the polymer properties considered most relevant with regard to the environmental fate and effects of polymers [7, 8, 12, 42].

The considered polymers sorb to organic substances with sorption increasing at higher MW. In addition, the anionic AA-P\&CoPs form poorly soluble complexes with divalent and polyvalent cations, and the cationic PQs strongly bind to DOC (including humic acids) and other negatively charged molecules. While the PEGs are more amenable to biodegradation, the considered AA-P\&CoPs and (based on the very limited database), PQs biodegrade only slowly. Nevertheless, an effective removal of all considered polymers from the water is expected in WWTPs, mainly due to sorption and subsequent precipitation. For polymers discharged to surface waters with the residual content of organic material in WWTP effluent, a sedimentation and slow biodegradation is assumed. Experimental data on the partitioning behaviour and mobility of the considered polymers in the aquatic environment are required to verify this assumption. When sewage sludge containing the polymers is applied to land, the polymers are likely to mostly remain at the site of entry into the soil, where a slow biodegradation is expected. Under field conditions, biodegradation rates of approx. $10 \%$ per year were determined for AAmAA-CoPs [92]. These biodegradation rates are much higher than those for plastics, i.e., water-insoluble synthetic polymers (available rough estimates for the lifetime of plastics in the environment are in the range of hundreds of years; see, e.g., $[76,160-162]$. To evaluate a potential accumulation of 


\section{Selected synthetic water-soluble organic polymers}

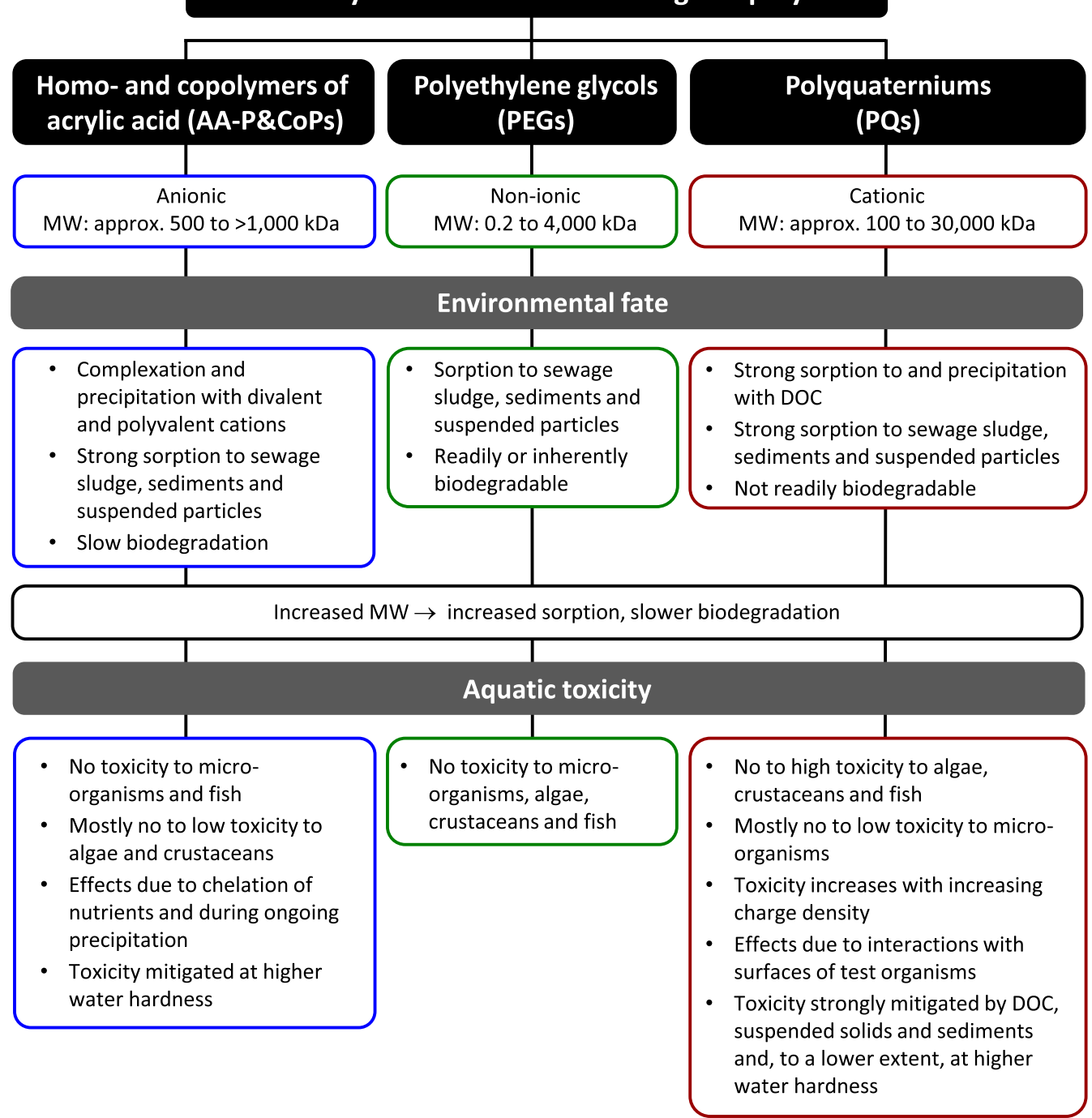

Fig. 1 Overview of the environmental fate and aquatic toxicity of the considered water-soluble synthetic polymers based on the evaluated data. Note that in the present evaluation, data for polymers with lower or higher MW than used in cosmetic products were also considered

the considered polymers in sediment or soil over longer time periods, information on the amounts released to the environment and further data on biodegradation in sediments and soil would be required.

An uptake of the considered polymers through biological membranes and tissue barriers into biota is limited by their large size (considerably above $1 \mathrm{kDa}$; the only exception are the lower MW PEGs, which are readily biodegradable), their charge (AA-P\&CoPs, $\mathrm{PQs}$ ) and the fact that sorption and complexation processes reduce their bioavailability (cf. $[11,103,104])$. Hence, bioaccumulation of the here considered water-soluble synthetic organic polymers is unlikely to pose a problem in the environment.
Based on the evaluated ecotoxicity data, the non-ionic PEGs are generally considered non-toxic to aquatic organisms. The anionic AA-P\&CoPs show no to low aquatic toxicity as also concluded in a recent study of DeLeo et al. [21]. Their effects result from a chelation of cationic nutrients [7] and from precipitation of the polymers [19]. Given that anionic polycarboxylates that are discharged with WWTP effluents are expected to have already bound to cations and sorbed to suspended solids, these mechanisms of toxicity are unlikely to be relevant in the environment. In laboratory tests, the cationic PQs often had higher toxicities to aquatic organisms than the non-ionic and anionic polymers. Their effects were attributed to electrostatic interactions with the negatively 


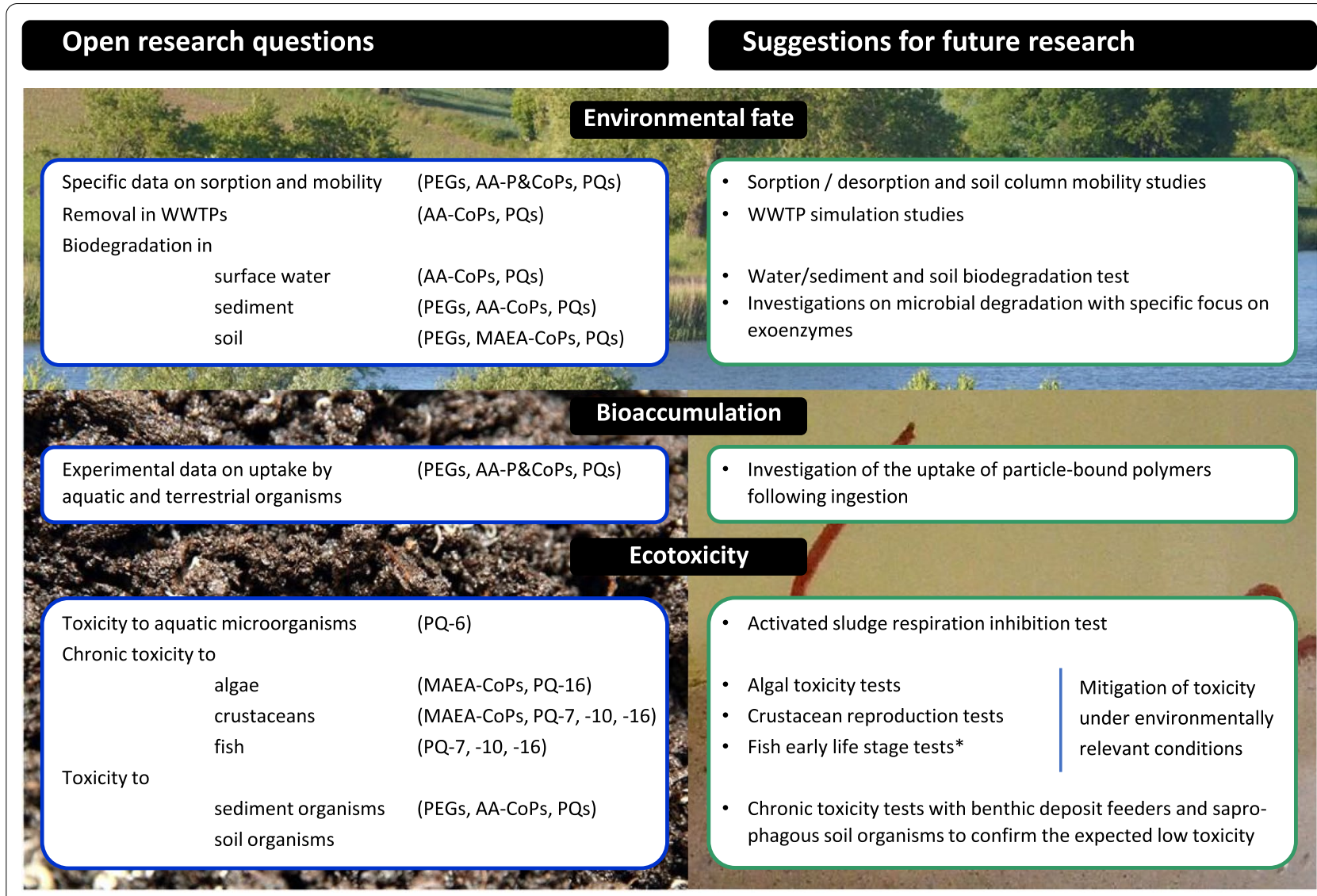

Fig. 2 Open research questions and suggestions for future research that were identified in the present review, which is mainly based on publicly available data. The polymers, for which the respective data were not available, are indicated in brackets. It is proposed to perform the suggested studies with representatives of the respective polymer class. *: Chronic fish tests (fish early life stage tests) are only recommended for polymers showing acute fish toxicity. They should only be performed after careful consideration of non-animal test methods, and if triggered in an environmental risk assessment

charged surfaces of the test organisms (e.g., [139]). Toxicities of the PQs to aquatic organisms were found to range from absent (i.e., no toxicity) to high, depending on the polymer (PQ-6, -7, -10, or -16), its charge density and MW, the test organism, and test conditions. The presence of DOC, suspended solids and sediment minerals, and-as shown for PQ-7-an increased water hardness mitigate aquatic toxicity of PQs (e.g., [117, 149]). Under typical environmentally relevant conditions, PQs are most likely sorbed to DOC (including humic acids) or suspended solids. This fact strongly reduces the probability of toxic effects on aquatic organisms. Still, the PQs appear as the most relevant in terms of ecotoxicity among the here considered polymers, and the dependence of their toxicity on their structure and the environmental conditions needs further investigation.

Results from laboratory toxicity tests with sediment and soil organisms were identified for P-AAs only, showing no toxicity. As toxicity in water-only tests is low
(AA-CoPs, PEGs) or strongly mitigated by sorption to DOC and particulate matter (PQs), no or a low toxicity to sediment and soil organisms could be assumed for the other considered polymers. However, this should be verified in water-sediment and terrestrial toxicity tests for representative polymers.

Relating exposure and effects to each other would be the next step towards an environmental risk assessment of the considered water-soluble synthetic organic polymers. While key aspects driving the fate of the polymers were addressed in the present study, it was not possible to derive realistic exposure concentrations for the relevant environmental compartments (surface water, sediments, and sludge-treated soil). An estimation of exposure, e.g., using the fate model EUSES according to the REACH guidance, currently suffers from the public non-availability of production and import volumes, and the scarcity of specific data on solid-water partitioning and removal during wastewater treatment. Due to the 
lack of sufficiently specific analytical methods, monitoring the concentrations of a given polymer in the environment is an extremely difficult task [11]. Hence, while data on toxicity to aquatic and, for P-AAs, benthic, and terrestrial organisms suggest low environmental concerns for the here considered polymers, this conclusion must be seen as preliminary given the absence of publicly available data on actual environmental exposure. Future evaluations of the environmental risks of polymers would greatly benefit from improved public availability of data, and further investigations of the behaviour and effects of polymers under environmentally relevant conditions. Figure 2 provides an overview of the most relevant research needs and of suggestions for future research. With regard to the assessment of ecotoxicity, the evaluation of available data suggests that methods may need to be adapted to account for the properties of the respective polymers, and further standardised to improve reproducibility (see also [117]). The composition of the test media (particularly hardness and TOC) and the experimental design (e.g., use of freshly prepared or aged polymer solutions) appear the most relevant aspects that require (further) standardisation for polymer testing. Moreover, guidance is needed with regard to mitigating factors in the European regulatory framework. In the U.S. framework, the mitigating effects of water hardness and DOC are considered when assessing potential environmental risks caused by poly(aliphatic acids) and cationic polymers, respectively [7, 12]. Mitigation approaches are also considered when assessing environmental risks of non-polymeric cationic substances [158].

\section{Supplementary Information}

The online version contains supplementary material available at https://doi. org/10.1186/s12302-021-00466-2.

Additional file 1: Definitions and explanations. Polymer selection process. Table S1. Identity and main physicochemical properties of the considered non-ionic polyethylene glycols (PEGs) as used in cosmetic products. Table S2. Identity and main physicochemical properties of the considered anionic homo- and copolymers of acrylic acid as used in cosmetic products. Table S3. Identity and main physicochemical properties of the considered cationic polyquaterniums (PQ-6, -7, -10 and -16) as used in cosmetic products. Table S4. Solid-water partition coefficients for the considered polymers. Table S5. Data on biodegradation and removal in wastewater treatment plants for polyethylene glycols (PEGs). Table S6. Data on biodegradation and removal in wastewater treatment plants for homo- (P-AA) and copolymers of acrylic acid (methacrylic acid-ethyl acrylate copolymer, MAEA-CoP, and acrylamide-acrylic acid copolymer, AAmAA-CoP). Table S7. Data on biodegradation and removal in wastewater treatment plants for the considered polyquaterniums (PQ-6, $-7,-10$ and -16). Table S8. Data on mobility of the considered polymers. Table S9. Ecotoxicity of polyethylene glycols (PEGs) to aquatic and terrestrial organisms. Table S10. Ecotoxicity of homo- (P-AA) and copolymers of acrylic acid (methacrylic acid-ethyl acrylate copolymer, MAEA-CoP, and acrylamide-acrylic acid copolymer, AAmAA-COP) to aquatic and terrestrial organisms. Table S11. Ecotoxicity of the considered polyquaterniums (PQ-6, -7, -10 and -16) to aquatic and terrestrial organisms. Additional abbreviations. Additional references.
Abbreviations

AA-CoPs: Copolymers of acrylic acid; AAmAA-CoP: Acrylamide-acrylic acid copolymer; AA-P\&CoPs: Homo- and copolymers of acrylic acid; d: Day(s); DADMAC: Diallyldimethylammonium chloride; DOC: Dissolved organic carbon; dw: Dry weight; ECETOC: European Centre for Ecotoxicology and Toxicology of Chemicals; EUSES: European Union System for the Evaluation of Substances; F: Flask; IKW: German Cosmetic, Toiletry, Perfumery and Detergent Association (Industrieverband Körperpflege und Waschmittel); $K_{d}$ : Solid-water partition coefficients; $K_{0 c}$ : Organic carbon-water partition coefficient; n.i.: Not indicated; MAEA-CoP: Methacrylic acid-ethyl acrylate copolymer; MW: Molecular weight; MW $_{n}$ : Number-average molecular weight; $\mathrm{MW}_{\mathrm{w}}$ : Weight-average molecular weight; P-AA: Homopolymer of acrylic acid; PEG: Polyethylene glycol; PLC: Polymers of low concern; polyDADMAC: Poly(dimethyldiallyammonium chloride); PQ: Polyquaternium; SCAS test: Semicontinuous activated sludge test; T: Tube; TOC: Total organic carbon; WWTP: Wastewater treatment plant.

\section{Acknowledgements}

Representatives from IKW and of some of its member companies provided confidential and non-confidential information on polymers used in cosmetic products, and contributed their expertise in discussions during the project. While the final draft of the manuscript was shared with such involved companies before submission, the conclusions and views expressed in this manuscript do not necessarily all reflect those of the IKW or all of its member companies.

\section{Authors' contributions}

KD and TJ developed the concept for the review, performed the literature and data search and evaluation, and drafted the manuscript. AC contributed to developing the concept for the manuscript, discussing the main findings and revising the draft manuscript. All authors read and approved the final manuscript.

\section{Funding}

The present study was initiated and funded by the IKW.

Availability of data and materials

All data analysed during this study are included in this published article and its supplementary information files.

\section{Ethics approval and consent to participate}

Not applicable.

\section{Consent for publication}

Not applicable.

\section{Competing interests}

The present study was funded by the German Cosmetic, Toiletry, Perfumery and Detergent Association (IKW).

Received: 16 November 2020 Accepted: 5 February 2021

Published online: 16 February 2021

References

1. US EPA (1997) Polymer exemption guidance manual EPA 744-B-97-001. United States Environmental Protection Agency, Office of Pollution Prevention and Toxics, Washington

2. ECHA (2012) Guidance for monomers and polymers. Version 2.0. European Chemicals Agency, Helsinki

3. Nguyen TQ, Kausch HH (1999) Molecular weight distribution - characterisation by GPC. In: Swallowe GM (ed) Mechanical properties and testing of polymers. Polymer Science and Technology Series, vol 3. Springer, Dordrecht, pp 151-155

4. EC (2006) Regulation (EC) No 1907/2006 of the European Parliament and of the Council of 18 December 2006 concerning the Registration, Evaluation, Authorisation and Restriction of Chemicals (REACH), establishing a European Chemicals Agency, amending Directive 1999/45/ EC and repealing Council Regulation (EEC) No 793/93 and Commission Regulation (EC) No 1488/94 as well as Council Directive 76/769/EEC 
and Commission Directives 91/155/EEC, 93/67/EEC, 93/105/EC and 2000/21/EC. Official J. Eur. Union L 396/1-849.

5. Postle M, Holmes P, Camboni M, Footitt A, Tuffnell N, Blainey M, Stevens G, Pye A (2012) Review of REACH with regard to the registration requirements on polymers. Final Report. Part A: Polymers. Prepared for the European Commission, DG Environment. Risk \& Policy Analysis Limited, Loddon

6. De Toni A, Saïdi N, Santos LR, Mudgal S (2015) Technical assistance related to the review of REACH with regard to the registration requirements on polymers. Final report, prepared for the European Commission, DG Environment. Bio By Deloitte.

7. Boethling RS, Nabholz JV (1997) Environmental assessment of polymers under the U.S. Toxic Substances Control Act. In: Hamilton JD, Sutcliffe R (eds) Ecological assessment of polymers Strategies for product stewardship and regulatory programs. Van Nostrand Reinhold, New York

8. OECD (2009) Data analysis of the identification of correlations between polymer characteristics and potential for health or ecotoxicological concern. ENV/JM/MONO(2009) 1. Organisation for Economic Cooperation and Development, Paris

9. ECETOC (2019) The ECETOC conceptual framework for polymer risk assessment (CF4Polymers). Technical report No 133-1. Version 1. European Centre for Ecotoxicology and Toxicology of Chemicals, Brussels.

10. Wood, (2020) Scientific and technical support for the development of criteria to identify and group polymers for registration/evaluation under REACH and their impact assessment. Final report for the European Commission. Wood E \& IS GmbH, Frankfurt/Main

11. ECETOC (2020) Applicability of analytical tools, test methods and models for polymer risk assessment. Technical report No. 133-2. Version 1. European Centre for Ecotoxicology and Toxicology of Chemicals, Brussels.

12. US EPA (2013) Interpretive assistance document for assessment of polymers. Sustainable Futures summary assessment.

13. Ward TC (1981) Molecular weight and molecular weight distributions in synthetic polymers. J Chem Educ 58:867-879

14. EU (2009) EU Regulation (EC) No 1223/2009 of the European Parliament and of the Council of 30 November 2009 on cosmetic products (recast). Official J Eur Union, L 342.

15. Lochhead RY, Gruber JV (1999) Appendix: Encyclopedia of polymers and thickeners for cosmetics. In: Goddard ED, Gruber JV (eds) Principles of polymer science and technology in cosmetics and personal care. Marcel Dekker Inc, New York

16. Fruijtier-Pölloth C (2005) Safety assessment on polyethylene glycols (PEGs) and their derivatives as used in cosmetic products. Toxicology 214:1-38

17. CIR (2019) Amended safety assessment of acrylates copolymers as used in cosmetics. Cosmetic Ingredients Review, Washington DC

18. ECETOC (1993) Polycarboxylate polymers as used in detergents. JACC Report No. 23. European Centre for Ecotoxicology and Toxicology of Chemicals, Brussels.

19. HERA (2014) Polycarboxylates used in detergents (Part I). Polyacrylic acid homopolymers and their sodium salts (CAS 9003-04-7). Version 3.0. Human \& Environmental Risk Assessment on ingredients of European household cleaning products.

20. Pecquet A, McAvoy D, Pittinger C, Stanton K (2019) Polymers used in US household cleaning products: assessment of data availability for ecological risk assessment. Integr Environ Assess Manag 15:621-632

21. DeLeo PC, Summers C, Stanton K, Lam MW (2020) Environmental risk assessment of polycarboxylate polymers used in cleaning products in the United States. Chemosphere 258:127242

22. Radoiu MT, Martin DI, Calinescu I, lovu H (2004) Preparation of polyelectrolytes for wastewater treatment. J Haz Mat 106:27-37

23. Lee CS, Robinson J, Chong MF (2014) A review on application of flocculants in wastewater treatment. Process Saf Environ Protec 92:489-508

24. Guezennec A-G, Michel C, Bru K, Touzé S, Desroche N, Mnif I, MotelicaHeino M (2015) Transfer and degradation of polyacrylamide based flocculants in hydrosystems: a review. Environ Sci Pollut Res 22:6390-6406

25. Orts WJ, Sojka RE, Glenn GM, Gross RA (1999) Preventing soil erosion with polymer additives. Polymer News 24:406-413

26. Sojka RE, Surapaneni A (2000) Potential use of polyacrylamide (PAM) in Australian agriculture to improve off and on-site environmental impacts and infiltration management. In: Polyacrylamides in irrigated agriculture. Report of Project No. UNE39, Land \& Water Resources Research and Development Corporation (LWRRDC).

27. Krauth DM, Bouldin JL, Green VS, Wren PS, Baker WH (2008) Evaluation of a polyacrylamide soil additive to reduce agricultural-associated contamination. Bull Environ Contam Toxicol 81:116-123

28. Becker N, Bennett D, Bolto B, Dixon D, Eldridge R, Le N, Rye C (2002) Measurement of flocculant residual by fluorescent tagging. Research Report No 14. CRC for Water Quality and Treatment, Salisbury.

29. John W (2008) Synthesis, properties and analysis of polyDADMAC for water purification. Dissertation, University of Stellenbosch.

30. Manickum T (2017) Occurrence, fate and preliminary environmental risk assessment of residual poly-diallyldimethyl ammonium chloride, and some disinfection by-products, in treated (potable), and environmental, waters in the Umgeni water catchment in Kwazulu-Natal (South Africa). SM J Public Health Epidemiol 3(2):1043

31. ECCC \& HC (2018) Draft screening assessment. Poly(amines) group. Chemical abstract service registry numbers 25988-97-0, 26062-79-3, 26590-05-6, 27967-29-9, 42751-79-1, 52722-38-0, 68130-99-4, 68134-56-5, 69418-26-4. Environment and Climate Change Canada, Health Canada.

32. Wilts EM, Herzberger J, Long TE (2018) Addressing water scarcity: cationic polyelectrolytes in water treatment and purification. Polym Int 67:799-814

33. Swift G (1994) Water-soluble polymers. Polym Degrad Stabil 45:215-231

34. Traverso-Soto JM, Lara-Martín PA, León VM, González-Mazo E (2013) Analysis of alcohol polyethoxylates and polyethylene glycols in marine sediments. Talanta 110:171-179

35. Hutanu D, Frishberg MD, Guo L, Darie CC (2014) Recent applications of polyethylene glycols (PEGs) and PEG derivatives. Mod Chem Appl 2:132

36. Rogers JD, Thurman EM, Ferrer I, Rosenblum JS, Evans MV, Mouser PJ, Ryan JN (2018) Degradation of polyethylene glycols and polypropylene glycols in microcosms simulating a spill of produced water in shallow groundwater. Environ Sci Process Impacts 21:256-268

37. Gruber JV (1999) Synthetic polymers in cosmetics. In: Goddard ED, Gruber JV (eds) Principles of polymer science and technology in cosmetics and personal care. Marcel Dekker Inc., New York.

38. Maitra J, Shukla VK (2014) Cross-linking in hydrogels-a review. Am J Polymer Sci 4(2):25-31

39. Substance Registry Services of the United States Environmental Protection Agency (USEPA). https://ofmpub.epa.gov/sor_internet/registry/ substreg/LandingPage.do. Accessed September 2019.

40. European Commission database for information on cosmetic substances and ingredients (Coslng). https://ec.europa.eu/growth/tools -databases/cosing/). Accessed September 2019.

41. Nabholz JV, Miller P, Zeeman M (1993) Environmental risk assessment of new chemicals under the Toxic Substances Control Act (TSCA) Section five. In: Landis WG, Hughes JS, Lewis MA (eds) Environmental toxicology and risk assessment. ASTM Special Technical Publication 1179. American Society for Testing and Materials, Philadelphia, pp 40-55.

42. Murgatroyd C, Barry M, Bailey K, Whitehouse P (1996). A review of polyelectrolytes to identify priorities for EQS development. R\&D Technical Report P21 for the Environment Agency (UK). WRc plc, Medmenham Marlow.

43. Klimisch H-J, Andreae M, Tillmann U (1997) A systematic approach for evaluating the quality of experimental toxicological and ecotoxicological data. Regul Toxicol Pharmacol 25:1-5

44. Nabholz V (2015) P2 Assessment of polymers. https://www.epa.gov/ sites/production/files/2015-05/documents/07-assessmentpolymers. pdf. Accessed Jan 2020.

45. Whipple WL, Zheng H (2014) Water-soluble free radical addition polymerizations: polyacrylamides. In: Reed WF, Alb AM (eds) From fundamentals to applications. Wiley, New York

46. Hennecke D, Bauer A, Herrchen M, Wischerhoff E, Gores F (2018) Cationic polyacrylamide copolymers (PAMs): environmental half life determination in sludge-treated soil. Environ Sci Eur 30:16

47. Spruijt E, Biesheuvel PM, de Vos WM (2015) Adsorption of charged and neutral polymer chains on silica surfaces: the role of electrostatics, volume exclusion, and hydrogen bonding. Phys Rev E Stat Nonlin Soft Matter Phys 91(1):012601 
48. Freeman MB, Bender TM (1993) An environmental fate and safety assessment for a low molecular weight polyacrylate detergent additive. Environ Technol 14:101-112

49. Letey J (1994) Adsorption and desorption of polymers on soil. Soil Sci 158:244-248

50. Xiong B, Dettam Loss R, Shields D, PawlikT, Hochreiter R, Zydney AL, Kumar M (2018) Polyacrylamide degradation and its implications in environmental systems. npj Clean Water 1:1-9

51. Obey TM, Griffiths PC (1999) Polymer adsorption: fundamentals. In: Goddard ED, Gruber JV (eds) Principles of polymer science and technology in cosmetics and personal care. Marcel Dekker Inc., New York

52. Sojka RE, Bjorneberg DL, Entry JA, Lentz RD, Orts WJ (2007) Polyacrylamide in agriculture and environmental land management. Adv Agron 92:75-162

53. Weston DP, Lentz RD, Cahn MD, Ogle RS, Rothert AK, Lydy MJ (2009) Toxicity of anionic polyacrylamide formulations when used for erosion control in agriculture. J Environ Qual 38:238-247

54. Cumming J, Hawker D, Chapman H, Nugent K (2011) The fate of polymeric quaternary ammonium salts from cosmetics in wastewater treatment plants. Water Air Soil Pollut 216:441-450

55. Podoll RT, Irwin KC, Brendlinger S (1987) Sorption of water-soluble oligomers on sediments. Environ Sci Technol 21:562-568

56. Szymanski A, Wyrwas B, Lukaszewski Z (2003) Determination of nonionic surfactants and their biotransformation by-products adsorbed on alive activated sludge. Water Res 37:281-288

57. Steber J, Wierich P (1985) Metabolites and biodegradation pathways of fatty alcohol ethoxylates in microbial biocenoses of sewage treatment plants. Appl Environ Microb 49:530-537

58. Opgenorth H-J (1992) Polymeric materials polycarboxylates. In: de Oude NT (ed) The handbook of environmental chemistry, vol 3. Part F. Springer, Berlin, pp 337-350

59. Rahbari R, Francois J (1992) Interactions between aluminium ions and acrylic acid-acrylamide copolymers in aqueous solution: 3. Influence of ionic strength on gelation and phase separation. Polymer 33:1449-1458

60. SDA (1996) Polycarboxylates. The Soap and Detergent Association

61. Hennes-Morgan EC, de Oude NT (1994) Detergents. In: Calow P (ed) Handbook of ecotoxicology, vol 2. Blackwell, Oxford, pp 130-154

62. Dow (2011) Product safety assessment. ACULYNTM anionic rheology modifiers, Dow Chemical Company, Midland

63. Maximova N (2004) Adsorption of lignin and lignin/cationic polymer complexes on cellulose fibres and their effect on sheet properties. Dissertation, Helsinki University of Technology.

64. Ishiguro M, Tan W, Koopal LK (2007) Binding of cationic surfactants to humic substances. Coll Surf A 306:29-39

65. Tan W, Norde W, Koopal LK (2011) Humic substance charge determination by titration with a flexible cationic polyelectrolyte. Geochim Cosmochim Ac 75:5749-5761

66. Cumming JL (2008) Environmental fate, aquatic toxicology and risk assessment of polymeric quaternary ammonium salts from cosmetic uses. Dissertation, Griffith University, Brisbane.

67. Cumming J, Hawker D, Chapman H, Nugent K (2011) Sorption of polymeric quaternary ammonium compounds to humic acid. Water Air Soil Pollut 214:5-11

68. Churchman GJ (2002) Formation of complexes between bentonite and different cationic polyelectrolytes and their use as sorbents for nonionic and anionic pollutants. Appl Clay Sci 21:177-189

69. Cheng P (2004) Chemical and photolytic degradation of polyacrylamides used in potable water treatment. MSc Thesis, University of South Florida.

70. Eubeler JP, Bernhard M, Knepper TP (2010) Environmental biodegradation of synthetic polymers II. Biodegradation of different polymer groups. Trends Anal Chem 29:84-100

71. Bernhard M, Eubeler JP, Zok S, Knepper TP (2008) Aerobic biodegradation of polyethylene glycols of different molecular weights in wastewater and seawater. Water Res 42:4791-4801

72. Bai M, Wilske B, Buegger F, Esperschütz J, Bach M, Frede H-G, Breuer $L$ (2015) Relevance of nonfunctional linear polyacrylic acid for the biodegradation of superabsorbent polymer in soils. Environ Sci Poll Res 22:5444-5452
73. Nyyssölä A, Ahlgren J (2019) Microbial degradation of polyacrylamide and the deamination product polyacrylate. Int Biodeter Biodegr 139:24-33

74. Gu J-D (2003) Microbiological deterioration and degradation of synthetic polymeric materials: recent research advances. Int Biodeter Biodegr 52:69-91

75. Eubeler JP, Bernhard M, Zok S, Knepper TP (2009) Environmental biodegradation of synthetic polymers I. Test methodologies and procedures. Trends Anal Chem 28:1057-1072

76. Andrady AL (2015) Plastics and environmental sustainability. Wiley, Hoboken

77. OECD (2006) Revised introduction to the OECD guidelines for the testing of chemicals. Section 3, part 1. Principles and strategies related to the testing of degradation of organic chemicals. Organisation for Economic Cooperation and Development, Paris

78. ECHA (2017) Guidance on information requirements and chemical safety assessment. Chapter R.7b: Endpoint specific guidance. Version 4.0. European Chemicals Agency, Helsinki.

79. Hansmann MA, Bookland EA, Keough TW, Larson RJ (1995) Biodegradation of various molecular weights of linear polyethylene glycol (PEG) in activated sludge. In: Abstracts of the 2nd SETAC world congress, Vancouver

80. Lara-Martín PA, González-Mazo E, Brwonawell BJ (2011) Multi-residue method for the analysis of surfactant residues and their degradation metabolites in aquatic systems by liquid chromatography-time-offlight-mass spectrometry. J Chromatogr A 1218:4799-4807

81. Federle TW, Itrich NR (2006) Fate of free and linear alcohol-ethoxylatederived fatty alcohols in activated sludge. Ecotox Environ Safe 64:30-41

82. Morrall SW, Dunphy JC, Cano ML, Evans A, McAvoy DC, Proce BP, Eckhoff WS (2006) Removal and environmental exposure of alcohol ethoxylates in US sewage treatment. Ecotox Environ Safe 64:3-13

83. Wind T, Stephenson RJ, Eadsforth CV, Sherren A, Roy R (2006) Determination of the fate of alcohol ethoxylate homologues in a laboratory continuous activated-sludge unit study. Ecotox Environ Saf 64:42-60

84. Zgoła-Grześkowiak A, GrześkowiakT, Zembrzuska J, Łukaszewski Z (2006) Comparison of biodegradation of poly(ethylene glycol)s and poly(propylene glycol)s. Chemosphere 64:803-809

85. Traverso-Soto JM, Rojas-Ojeda P, Sanz JL, González-Mazo E, Lara-Martín PA (2016) Anaerobic degradation of alcohol ethoxylates and polyethylene glycols in marine sediments. Sci Total Environ 544:118-124

86. Abdalla AL, Regitano JB, Tornisielo VL, Marchese L, Peçanha MRSR, Vitti DMSS, Smith T (2005) Biodegradation of polyethylene glycol (PEG) in three tropical soils using radio labelled PEG. Anim Feed Sci Tech 122:187-193

87. Hamilton JK, Reinert DH, Freeman MB (1994) Aquatic risk assessment of polymers. Environ Sci Technol 28:187A-192A

88. BASF (2015) Safety data sheet according to Regulation (EC) No. 1907/2006. Product: Magnafloc ${ }^{\circledR}$ 1011. Version 2.5.

89. BASF (2016) Safety data sheet according to Regulation (EC) No. $1907 / 2006$ as amended from time to time. Product: Luviflex ${ }^{\circledR}$ Soft. Version 3.0.

90. Guzzo J, Guezennec A-G (2015) Degradation and transfer of polyacrylamide based flocculent in sludge and industrial and natural waters. Environ Sci Pollut Res 22:6387-6389

91. Wolter M, In der Wiesche C, Zadrazil F, Hey S, Haselbach J, Schnug E (2002) Biologische Abbaubarkeit synthetischer superabsorbierender Bodenhilfsstoffe. Landbauforschung Völkenrode 52(1):43-52

92. Entry JA, Sojka RE, Hicks BJ (2008) Carbon and nitrogen stable isotope ratios can estimate anionic polyacrylamide degradation in soil. Geoderma 145:8-16

93. Dow (2011) Safety Data Sheet: UCARE ${ }^{\text {TM }}$ Polymer LR-30M. Dow Chemical Company Limited, UK

94. Dow (2015) Safety data sheet: UCARE ${ }^{\mathrm{TM}}$ Polymer JR-400. Version 12.0. Dow Chemical Company Limited, UK.

95. BASF (2012) Safety data sheet according to Regulation (EC) No. 1907/2006. Product: Luviquat ${ }^{\circledR}$ HM 552. Version 2.0. BASF, Ludwigshafen.

96. BASF (2012) Safety data sheet according to Regulation (EC) No. 1907/2006 as amended from time to time. Product: Luviquat ${ }^{\circledR}$ FC 550 Version 1.0. BASF, Ludwigshafen. 
97. BASF (2016) Luviquat ${ }^{\circledR}$ FC 370. Sicherheitsdatenblatt gemäß Verordnung (EG) Nr. 1907/2006 in der jeweils gültigen Fassung. Version 3.0

98. BASF (2017) Safety data sheet. Luviquat ${ }^{\circledR}$ Excellence. Version 3.1.

99. 3V Sigma (2016) Safety data sheet: Conditioner P7NA. 3V Sigma S.p.a., Bergamo.

100. Razali MAA, Ahmad Z, Ahmad MSB, Ariffin A (2011) Treatment of pulp and paper mill wastewater with various molecular weight of polyDADMAC induced flocculation. Chem Eng J 166:529-535

101. UBA (2018) Klärschlammentsorgung in der Bundesrepublik Deutschland. Umweltbundesamt, Dessau-Roßlau

102. Sack TM, Wilner J, Cutie SS, Blanchette AR, Johnson BN (1998) Monitoring soil column mobility of cross-linked and soluble polyacrylates using gel permeation chromatography. Environ Sci Technol 32:2474-2479

103. Müller M, Nendza M (2007) Literature study: Effects of molecular size and lipid solubility on bioaccumulation potential. FKZ 36001043 . Final report for the German Environment Agency. Fraunhofer Institute for Molecular Biology and Applied Ecology, Schmallenberg.

104. Barron MG (1990) Bioconcentration. Environ Sci Technol 24:1612-1618

105. Opperhuizen A, Van der Velde EW, Gobas FAPC, Liem DAK, Van der Stehen JMD, Hutzinger O (1985) Relationship between bioconcentration in fish and steric factors of hydrophobic chemicals. Chemosphere 14:1871-1896

106. Armitage JA, Erickson RJ, Luckenbach T, Ng CA, Prosser RS, Arnot JA, Schirmer K, Nichols JW (2017) Assessing the bioaccumulation potential of ionizable organic compounds: current knowledge and research priorities. Environ Toxicol Chem 36:882-889

107. De Wolf W, Comber M, Douben P, Gimeno S, Holt M, Léonard M, Lillicrap A, Sijm D, van Egmond R, Weisbrod A, Whale G (2007) Animal use replacement, reduction and refinement: development of an integrated testing strategy for bioconcentration of chemicals in fish. Integr Environ Assess Manag 3:3-17

108. Arnot JA, Arnot Ml, Mackay D, Couillard Y, MacDonald D, Bonnell M, Doyle P (2010) Molecular size cutoff criteria for screening bio-accumulation potential: fact or fiction? Integr Environ Assess Manag 6:210-224

109. ECHA (2017) Guidance on information requirements and chemical safety assessment. Chapter R.11: PBT/VPvB assessment. Version 3.0. European Chemicals Agency, Helsinki.

110. EC (2011) Commission regulation (EU) No 253/2011 of 15 March 2011 amending Regulation (EC) No 1907/2006 of the European Parliament and of the Council on the registration, evaluation, authorisation and restriction of chemicals (REACH) as regards Annex XIII. Official J Eur Union L 69/7.

111. SCHER (2010) Opinion on updated HERA report on polycarboxylates in detergents (HERA report April 2009, version 2). Scientific Committee on Health and Environmental Risks, European Commission, Brussels

112. EFSA (2016) Recent developments in the risk assessment of chemicals in food and their potential impact on the safety assessment of substances used in food contact materials. EFSA J 14:4357

113. ECHA (2017) Guidance on information requirements and chemical safety assessment. Chapter R.7c: Endpoint specific guidance. Version 4.0. European Chemicals Agency, Helsinki.

114. Liber K, Weber L, Lévesque C (2005) Sublethal toxicity of two wastewater treatment polymers to lake trout fry (Salvelinus namaycush). Chemosphere 61:1123-1133

115. Anderson EL, Samaniego PC, Bühlmann P (2019) Indirect potentionmetric determination of polyquaternium polymer concentrations by equilibrium binding to 1-dodecyl sulfate. Analyt Sci 35:679-684

116. Brakstad OG, Altin D, Davies EJ, Aas M, Nordtug T (2020) Interaction between microalgae, marine snow and anionic polyacrylamide APAM at marine conditions. Sci Total Environ 705:135950

117. Salinas ER, Bozich JS, Kolbenschlag S, Kary-Heinrich M, Hopp PW, Lukas R, Zok S, Hidding B (2020) Aquatic testing guidelines insufficiently control the influence of dilution water TOC and hardness on cationic polymer toxicity-a proposal to improve standardized test procedures. Chemosphere 259:127473

118. Wagner PM, Nabholz JV, Kent RJ (1995) The new chemicals process at the Environmental Protection Agency (EPA): structure-activity relationships for hazard identification and risk assessment. Toxicol Lett 79:67-73

119. UN (2015) Globally harmonized system of classification and labelling of chemicals (GHS). 6th ed. New York.
120. OECD (2011) Freshwater alga and cyanobacteria, growth inhibition test. OECD guidelines for the testing of chemicals, No 201. Organisation for Economic Cooperation and Development, Paris

121. OECD (2004) Daphnia sp., acute immobilisation test OECD guidelines for the testing of chemicals, No 202. Organisation for Economic Cooperation and Development, Paris

122. OECD (2019) Fish, acute toxicity test OECD guidelines for the testing of chemicals, No 203. Organisation for Economic Cooperation and Development, Paris

123. OECD (2012) Daphnia magna reproduction test. OECD guidelines for the testing of chemicals, No 211. Organisation for Economic Cooperation and Development, Paris

124. OECD (2013) Fish, early-life stage toxicity test OECD guidelines for the testing of chemicals, No 210. Organisation for Economic Cooperation and Development, Paris

125. Nabholz JV, Zeeman M (1991) Environmental concerns of polymers. Memorandum. Office of Pesticides and Toxic Substances, US EPA. Washington DC.

126. Brenntag (2012) Safety data sheet according to Regulation (EC) No. 1907/2006. Polyethyleneglycol 400 / Bulk. Version 2.0.

127. Dow (2015) Safety data sheet: Carbowax ${ }^{\top \mathrm{M}}$. Polyethylene glycol 600 . Dow Chemical Company, Midland.

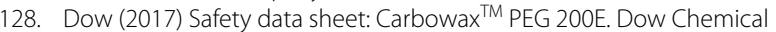
Company.

129. Harford AJ, Hogan AC, van Dam RA (2010) Ecotoxicological assessment of a polyelectrolyte flocculant. Report 575 for the Australian Goverment, Department of the Environment, Water, Heritage and the Arts, Darwin.

130. Harford AJ, Hogan AC, Jones DR, van Dam RA (2011) Ecotoxicological assessment of a polyelectrolyte flocculant. Water Res 45:6393-6402

131. C.S.B. GmbH (2011) Sicherheitsdatenblatt gemäß 1907/2006/EG, Artikel 31. C.S.B, GmbH, Krefeld

132. Hatami M, Banaee M, Nematdoost Haghi B (2019) Sub-lethal toxicity of chlorpyrifos alone and in combination with polyethylene glycol to common carp (Cyprinus carpio). Chemosphere 219:981-988

133. BASF (2016) Safety data sheet according to Regulation (EC) No. $1907 / 2006$ as amended from time to time. Product: Sokalan ${ }^{\circledR}$ PA $25 \mathrm{CL}$ Granules. Version 1.2.

134. Greenaway P (1985) Calcium balance and moulting in the crustacea. Biol Rev 60:425-453

135. Buczek SB, Cope WG, McLaughlin RA, KwakTJ (2017) Acute toxicity of polyacrylamide flocculants to early life stages of freshwater mussels. Environ Toxicol Chem 36:2715-2721

136. Poléo ABS (1995) Aluminium polymerization-a mechanism of acute toxicity of aqueous aluminium to fish. Aquat Toxicol 31:347-356

137. Biesinger KE, Stokes GN (1986) Effects of synthetic polyelectrolytes on selected aquatic organisms. J Water Pollut Control Fed 58:207-213

138. Jennings MC, Minbiole KP, Wuest WM (2015) Quaternary ammonium compounds: an antimicrobial mainstay and platform for innovation to address bacterial resistance. ACS Infect Dis 1:288-303

139. Nolte TM, Peijnenburg WJGM, Hendriks AJ, van de Meent D (2017) Quantitative structure-activity relationships for green algae growth inhibition by polymer particles. Chemosphere 179:49-56

140. OECD (2010) Activated sludge, respiration inhibition test (carbon and ammonium oxidation). OECD guidelines for the testing of chemicals, No 209. Organisation for Economic Cooperation and Development, Paris

141. NICNAS (1997) Full public report. Copolymer in polyquaternium-34. File No: NA/475. National Industrial Chemicals Notification and Assessment Scheme, Camperdown.

142. NICNAS (2009) Full public report. Polyquaternium-76. File No: LTD/1408 National Industrial Chemicals Notification and Assessment Scheme, Marrickville.

143. Xiong W, Tang Y, Shao C, Zhao Y, Jin B, Huang T, Miao Y, Shu L, Ma W, XU X, Tang R (2017) Prevention of cyanobacterial blooms using nanosilica: a biomineralization-inspired strategy. Environ Sci Technol 51:12717-12726

144. Branyikova I, Prochazkova G, Potocar T, Jezkova Z, BranyikT (2018) Harvesting of microalgae by flocculation Fermentation 4:93 
145. Pugazhendhi A, Shobana S, Bakonyi P, Nemestóthy N, Xia A, Banu R, Kumar G (2019) A review on chemical mechanism of microalgae flocculation via polymers. Biotechnol Rep 21:e00302

146. Block SS (2001) Disinfection, sterilisation and preservation. Lippincott Williams \& Wilkins, Philadelphia

147. SNF S.A.S. (2007) Material safety data sheet. FlocareTM C 106 (Polyquaternium-6). SNF S.A.S., Andrezieux Cedex.

148. Kalekimya (2014) Safety data sheet according to Regulation (EC) No. 453/2010. Polyquaternium-7. Kale Kimya Kimyevi Maddeler A.S., Kocaeli.

149. Cary GA, McMahon JA, Kuc WJ (1987) The effect of suspended solids and naturally occurring dissolved organics in reducing the acute toxicities of cationic polyelectrolytes to aquatic organisms. Environ Toxicol Chem 6:469-474

150. Hall WS, Mirenda RJ (1991) Acute toxicity of wastewater treatment polymers to Daphnia pulex and the fathead minnow (Pimephales promelas) and the effects of humic acid on polymer toxicity. J Water Pollut Control Fed 63:895-899

151. de Rosemond SJC, Liber K (2004) Wastewater treatment polymers identified as the toxic component of a diamond mine effluent. Environ Toxicol Chem 23:2234-2242

152. Rowland CD, Burton GA Jr, Morrison SM (2000) Implication of polymer toxicity in a municipal wastewater effluent. Environ Toxicol Chem 19:2136-2139

153. Pereira JL, Vidal T, Gonçalves FJM, Gabriel RG, Costa R, Rasteiro MG (2018) Is the aquatic toxicity of cationic polyelectrolytes predictable from selected physical properties? Chemosphere 202:145-153

154. BASF (2016) Safety data sheet: Dehyquart ${ }^{\circledR}$ CC7 BZ. Version 2.0. BASF, Ludwigshafen.

155. Cumming JL, Hawker DW, Nugent KW, Chapman HF (2008) Ecotoxicities of polyquaterniums and their associated polyelectrolyte-surfactant aggregates (PSA) to Gambusia holbrooki. J Environ Sci Health A 43:113-117

156. Muir MM, Kosteretz KG, Lech JJ (1997) Localization, depuration, bioaccumulation and impairment of ion regulation associated with cationic polymer exposure in rainbow trout (Oncorhynchus mykiss). Xenobiotica 10:1005-1014

157. Goodrich MS, Dulak LH, Friedman MA, Lech JJ (1991) Acute and long-term toxicity of water-soluble cationic polymers to rainbow trout (Oncorhynchus mykiss) and the modification of toxicity by humic acid. Environ Toxicol Chem 10:509-515

158. OECD (2019) Guidance document on aqueous-phase aquatic toxicity testing of difficult test chemicals. Series on testing and assessment. No 23 (second edition). ENV/JM/MONO(2000)6/REV1. Organisation for Economic Cooperation and Development, Paris.

159. ECHA (2016) Guidance on information requirements and chemical safety assessment. Chapter R.16: Environmental exposure assessment. Version 3.0. European Chemicals Agency, Helsinki.

160. Moore CJ (2008) Synthetic polymers in the marine environment: a rapidly increasing, long-term threat. Environ Res 108:131-139

161. Barnes DK, Galgani F, Thompson RC, Barlaz M (2009) Accumulation and fragmentation of plastic debris in global environments. Philos Trans $R$ Soc Lond B 364:1985-1998

162. EC (2011) Plastic waste: ecological and human health impacts. In-depth report. Science for environment policy. DG Environment News Alert Service

\section{Publisher's Note}

Springer Nature remains neutral with regard to jurisdictional claims in published maps and institutional affiliations.

\section{Submit your manuscript to a SpringerOpen ${ }^{\circ}$ journal and benefit from:}

- Convenient online submission

- Rigorous peer review

- Open access: articles freely available online

- High visibility within the field

- Retaining the copyright to your article

Submit your next manuscript at springeropen.com 